\title{
Three-Dimensional Circulation in the NW Africa Coastal Transition Zone
}

\author{
V.M. Benítez-Barrios ${ }^{\mathrm{a}, *}$, J.L. Pelegrí ${ }^{\mathrm{b}}$, A. Hernández-Guerra ${ }^{\mathrm{a}}$, K.M.M. Lwiza ${ }^{\mathrm{c}}$, D. \\ Gomis $^{\mathrm{d}}$, P. Vélez-Belchíe, S. Hernández-León ${ }^{\mathrm{a}}$ \\ ${ }^{a}$ Facultad de Ciencias del Mar, Universidad de Las Palmas de Gran Canaria, E-35017, Las \\ Palmas, Spain \\ ${ }^{b}$ Institut de Ciències del Mar (CSIC), E-08003, Barcelona, Spain \\ ${ }^{c}$ Marine Sciences Research Center, State University of New York, Stony Brook, NY 11794-5000, \\ USA \\ ${ }^{d}$ Institut Mediterrani d'Estudis Avançats (CSIC-UIB), E-07071, Palma de Mallorca, Spain \\ ${ }^{e}$ Instituto Español de Oceanografía, Centro Ocenográfico de Canarias, E-38005, Santa Cruz de \\ Tenerife, Spain
}

\begin{abstract}
High-resolution data collected southeast of the Canary Islands during late winter 2006 are analyzed to describe the hydrography and three-dimensional circulation in the coastal transition zone off NW Africa. The data are optimally interpolated over a regular grid, the geostrophic velocity field is calculated and the Q-vector formulation of the omega equation is used to compute the quasi-geostrophic (QG) mesoscale vertical velocity. The coastal transition zone is divided into upwelling, frontal and offshore regions with distinct physical and dynamic characteristics. The upwelling region is characterized by cold and weakly stratified waters flowing towards the equator, with a poleward undercurrent of approximately $0.05 \mathrm{~m} \mathrm{~s}^{-1}$ over the continental slope. The frontal region exhibits a southwestward baroclinic jet associated with cross-shore raising isopycnals; the jet transport is close to $1 \mathrm{~Sv}$, with maximum velocities of $0.18 \mathrm{~m} \mathrm{~s}^{-1}$ at surface decreasing to $0.05 \mathrm{~m} \mathrm{~s}^{-1}$ at 300
\end{abstract}

${ }^{*}$ Corresponding author 
db. Vertical sections across the frontal region show the presence of deep eddies probably generated by the topographic blocking of the islands to the southward current, as well as much shallower eddies that likely have arisen as instabilities of the baroclinic upwelling jet. The QG mesoscale vertical velocity field is patchy, estimated to range from -18 to $12 \mathrm{~m} \mathrm{day}^{-1}$, with the largest absolute values corresponding to an anticyclonic eddy located south of Fuerteventura island. These values are significantly larger than estimates for other vertical velocities: diapycnal vertical velocities associated with mixing in the frontal region (a few $\mathrm{m} \mathrm{day}^{-1}$ ), and wind-induced vertical velocities (non-linear Ekman pumping arising from the interaction between the wind stress and the background vorticity, maximum values of a few m day ${ }^{-1}$; linear Ekman pumping due to the divergence of Ekman transport, a fraction of a meter per day; or the coastal constraint in the upwelling region, about $0.7 \mathrm{~m} \mathrm{day}^{-1}$ ). However, the patchiness in both the QG mesoscale vertical velocity and the non-linear Ekman pumping velocity cause their integrated vertical transports to be one order of magnitude smaller than either coastal Ekman transport $(0.08 \mathrm{~Sv})$, integrated linear Ekman pumping (-0.05 Sv) or diapycnal transfer (about 0.1 to $0.2 \mathrm{~Sv}$ ). The pattern of the near-surface fluorescence field is a good indicator of these different contributions, with large homogeneous values in the coastal upwelling region and a patchy structure associated with the offshore mesoscale structures.

Keywords: Eastern boundaries; Canary Upwelling System; Quasi-geostrophic omega equation; Vertical velocity; Frontal zones; Nutrient supply 


\section{Introduction}

The most prominent characteristic of the coastal transition zone (CTZ) off NW Africa is the presence of a coastal upwelling frontal system, a transition region between stratified offshore waters and relatively homogeneous upwelled waters. The visible, sea-surface, expression of this frontal system is usually simply referred as front (Bowman and Iverson, 1978). This CTZ has received considerable attention in the past. Major research started during the Cooperative Investigation of the Northern Part of the Eastern Central Atlantic (CINECA), held between 1970 and 1977, with nearly one hundred scientific cruises aimed at studying the upwelling region off NW Africa (e.g. Hughes and Barton, 1974; Mittelstaedt et al., 1975; Brockman et al., 1977; Tomczak, 1978; Manríquez and Fraga, 1982; Mittelstaedt, 1983). During the eighties the focus of the research turned to the deep ocean, partly motivated by regional political instability and partly because of the global objectives of the World Ocean Circulation Experiment (e.g. Käse et al., 1986; Krauss, 1986; Fiekas et al., 1992; Müller and Siedler, 1992; Arhan et al., 1994). Since the beginning of the nineties major attention shifted to the physical and biological characteristics of mesoscale structures, eddies and filaments, either associated to the Canary Islands or to the upwelling region (e.g. Arístegui et al., 1994; Hagen et al., 1996; Barton et al., 1998; Sangrà et al., 2005; Sangrà et al., 2007, 2009).

During the late nineties the Canary Islands Azores Gibraltar (CANIGO) project had sufficient spatial coverage and resolution to investigate the CTZ off NW Africa (Parrilla et al., 2002). In the lifetime of CANIGO, permanent moorings, scientific and opportunity cruises, and remote sensing data provided an improved 
view of the spatio-temporal variability of the NW Africa system (e.g. Van Camp et al., 1991; Nykjaer and van Camp, 1994; Hernández-Guerra and Nykjaer, 1997; Pacheco and Hernández-Guerra, 1999; Hernández-Guerra et al., 2001; Knoll et al., 2002; Tejera et al., 2002; Hernández-Guerra et al., 2003; Pelegrí et al., 2005a; Pelegrí et al., 2005b; García-Muñoz et al., 2005; Machín et al., 2006a). One main outcome of the CANIGO program was to realize that a major fraction of the eastern boundary recirculation of central waters, or Canary Current (CC), occurs in the CTZ, a relatively narrow region where intense transfer takes place between subsurface and surface waters. This easternmost branch of the $\mathrm{CC}$, linked to the coastal upwelling jet, has been referred as the Canary Upwelling Current (CUC) (Pelegrí et al., 2005b, 2006). The existence of such localized along-slope, equatorward, transport has also been described for another major eastern boundary region, the California Current System (e.g. Huyer et al., 1998, and references therein).

All the above studies have greatly contributed to the knowledge of the CTZ in terms of physico-biogeochemical water properties and meso- and large-scale structures, horizontal circulation and spatio-temporal variability. Nevertheless, the delicate interplay of horizontal and vertical motions in the CTZ yet remains quite unknown. The complexity of estimating the three-dimensional (3D) flow lies on the difficulty to measure the vertical velocity. Horizontal velocities in the CTZ have been determined either from drifters (Barton et al., 2004; Sangrà et al., 2005; Sangrà et al., 2007), altimetry data (Sangrà et al., 2009), moored currentmeters (Hernández-Guerra et al., 2003), ship-borne ADCP (Knoll et al., 2002) or by applying the thermal wind relation to density profiles (Hernández-Guerra et al., 2001; Barton et al., 2004; Hernández-Guerra et al., 2005; Sangrà et al., 
2007). The vertical velocity associated to the internal wave field may reach up to $\mathrm{O}\left(10^{-2}\right) \mathrm{m} \mathrm{s}^{-1}$, therefore also being a measurable variable (van Aken et al., 2007). However, these are relatively fast motions, with time scales from minutes to hours.

Vertical motions at the CTZ with time scales from days to weeks are notoriously difficult to measure because of their small magnitude, typically five to six orders of magnitude less than the horizontal velocities. They have to be inferred indirectly, from a laborious analysis of the distribution of other measured variables, hence very little is yet known about their spatial structure in the CTZ. These vertical motions may arise from several mechanisms: as the result of wind forcing, through unstable vertical motions at the upwelling frontal system, and because of ageostrophic imbalances associated to mesoscale dynamics. Hereafter, when we refer to vertical motions we will always be talking about these processes; they are briefly revised in the following paragraphs.

First, the wind-induced contribution may be directly estimated from the local winds. Inhomogeneities in Ekman transport, either because of the coastal constraint or because of spatial variations in surface winds, induce linear Ekman convergence or divergence (e.g. Gill, 1982). Such convergent and divergent motions lead to vertical displacements of the isopycnals, e.g. in the CTZ divergence causes upwelling and the appearance of cold waters at the surface. Additionally, non-linear Ekman pumping may arise from the differential transport of relative vorticity gradients by the wind.

Second, the frontal region is often critically stable (Kundu and Beardsley, 
1991), i.e. the gradient Richardson number is close to a critical value. In this case shear-induced vertical displacements are unstable and lead to the vertical redistribution of density or, effectively, to the diapycnal (cross-isopycnal) transfer of water properties. This contribution is difficult to assess and here we will estimate it by assuming that the net vertical transfer has to close the large-scale horizontal balance, essentially the same procedure followed by inverse models (e.g. Machín et al., 2006a).

Finally, there are vertical motions associated with different phases of mesoscale structures, analogous to what happens in atmospheric motions (Keyser and Shapiro, 1986). We will assess them through the Q-vector version of the quasi-geostrophic (QG) omega equation (Hoskins et al., 1978), a procedure widely used in the literature (Tintoré et al., 1991; Pollard and Regier, 1992; Allen and Smeed, 1996; Rudnick, 1996; Gomis et al., 2002; Mouriño et al., 2004; Shearman et al., 1999).

This work aims at investigating the 3D circulation in the CTZ off NW Africa, with special attention to two aspects. One main objective is to explore the characteristics of the different dynamic regimes encountered as we move in the crossshore direction away from the continental platform. In particular, we demonstrate that the frontal region not only separates upwelling from offshore waters but is also a source of shallow baroclinic mesoscale features, substantially different from the more barotropic eddies generated through the interaction of the $\mathrm{CC}$ with the islands. The other principal aim is to quantify the different contributions to the vertical motion, namely vertical velocities induced by wind, mesoscale structures and shear mixing. We will see that it is not possible to clearly separate these dif- 
ferent vertical contributions, nevertheless it is possible to give order of magnitude estimates of their size.

In order to examine these ideas we concentrate in a relatively small region south of the Canary Islands, using data with high spatial resolution from an oceanographic cruise carried out in late winter 2006. This cruise was part of CONAFRICA, a multidisciplinary research project focused on the zooplankton and ictioplankton drift within filaments emanating from the NW African upwelling region. Section 2 presents the dataset and the interpolation method used to map the measured hydrographic variables onto a regular grid. The data interpolation is critical when high-order derived variables such as vertical velocity are to be obtained from the mapped observed variables. Section 3 describes the methodology used to assess the different contributions to vertical motion, with emphasis on the QG omega equation. Section 4 presents a general view of the horizontal and vertical hydrographic structure of the CTZ as obtained from observations. Section 5 analyzes the results and discusses the main dynamic processes associated with the distinct regions of the CTZ, as well as their influence on the fluorescence distribution. We close the paper in Section 6 by summarizing the major findings and the remaining uncertainties. An Appendix is included which gives error estimates for vertical velocities. 


\section{Data analysis}

\subsection{Dataset}

During the R/V Hespérides survey (22 March - 7 April 2006) 81 ConductivityTemperature-Depth (CTD) stations were performed in a $200 \times 100 \mathrm{~km}^{2}$ domain located south of the eastern Canary Islands. The stations were distributed along transects parallel to the African coast (Figure 1) with a meridional and zonal spacing of about $20 \mathrm{~km}$. The CTD profiles were obtained with a SeaBird 911Plus, equipped with a fluorometer. Raw profiles were interpolated on a 2-db interval and generally restricted to the top $500 \mathrm{db}$ (or the sea bed where shallower).

Wind data from the SeaWind scatterometer onboard the QuikSCAT satellite were downloaded from the CERSAT site (http://www.ifremer.fr/cersat/). Data are available on gridded fields of $0.5^{\circ}$ latitude and $0.5^{\circ}$ longitude at daily resolutions. Both the spatial distribution of the mean winds during the time of the cruise (Figure 1a) and the time series of wind speed and direction averaged over the survey area (Figure 2; the averaging area is highlighted as a gray rectangle in Figure 1) show the dominance of upwelling favourable conditions. Sporadic downwelling-favourable winds occurred at the beginning and end of February, and just before the cruise, but the sampling was carried out during an upwelling event. The QuikSCAT data is relatively low resolution but provides a real-time view of the wind in the study area and its resolution is good enough to determine the Ekman transports into or out of our domain. Additionally, in order to estimate

lineal and non-lineal pumping, we used high-horizontal resolution $(10 \mathrm{~km} \times 10$ $\mathrm{km}$ ) three-day reanalysis data as obtained from the European Centre for MediumRange Weather Forecasts (ECMWF). 
During the cruise near real-time Chlorophyll-a (Chl-a) estimates, derived from the Seaviewing Wide Field-of-view Sensor (SeaWiFS), were processed by the Remote Sensing Center at the University of Las Palmas and used onboard to guide the sampling. Sea Surface Temperature (SST) images from the Advanced Very High Resolution Radiometer (AVHRR) and Chl-a images are used in this study to help understand the physical processes occurring in the region.

\subsection{Optimal statistical interpolation}

In order to compute spatial derivatives of the observed variables and hence to diagnose the vertical velocity field, the hydrographic variables are to be interpolated from the unevenly distributed observations points onto a $3 \mathrm{D}$ regular grid. A widely applied method is the Optimal Statistical Interpolation (OSI) scheme, originally developed by Gandin (1965) for meteorological data and first described in an oceanographic context by Bretherton et al. (1976) (for a review see Gomis et al., 2001).

The output grid consists of $21 \times 44$ points separated approximately $5 \mathrm{~km}$ in the offshore and alongshore directions. The grid-point spacing is a compromise between the spatial resolution and minimizing errors on spatial derivatives. On one hand, the spatial resolution of the output field is constrained by the station separation but has to be good enough to resolve the spatial scales of interest. On the other hand, the accuracy of spatial derivatives is usually increased using a coarse grid. In the vertical direction we use 34 levels equally spaced at $15 \mathrm{db}$ and covering from 5 to $500 \mathrm{db}$. The mean field for all variables is computed by fit- 
ting a second order polynomial to the observations. The horizontal characteristic scale of the correlation model (related to the size of the dominant structures) and the noise-to-signal ratio are set to $20 \mathrm{~km}$ and 0.01 , respectively. Additionally, in order to avoid aliasing problems, the spatial scales that cannot be resolved by the sampling are filtered out by convolving the classical OSI scheme with a normalerror filter (Gomis et al., 2001); the cut-off wavelength of the filter is set to $40 \mathrm{~km}$ (twice the separation distance between stations). A sensitivity analysis on how the derived variables change with these interpolation parameters has been carried out and the main results are shown in Appendix A.

The described interpolation scheme can be readily applied to temperature $T$ and salinity $S$, from which other variables such as potential temperature $\theta$, potential density anomaly (referred to the sea surface) $\sigma_{\theta}$ and neutral density $\gamma_{n}$ (Jackett and McDougall, 1997) may be calculated. To compute the dynamic height we set $500 \mathrm{db}$ as the reference level, which is our deepest sampled water depth. This is not far from the lowest limit of the North Atlantic Central Water (NACW), about 600-700 db, and is close to no-motion reference levels suggested by other authors for the area south of the Canary Islands (Olbers et al., 1985; Pelegrí et al., 2006; Pastor et al., 2008). Since the surveyed area included shelf stations, we chose the layer thickness (dynamic height referred to the level immediately below) as the variable to be interpolated onto the grid points. Following this simple procedure effectively sets the no-motion reference level to continue onshore along the sea bottom, as in Csanady (1979). The dynamic height is then determined by integrating up from the reference level, and other dynamical variables can be easily derived from the interpolated density and dynamic height fields through finite dif- 
ferences. Hereafter, despite differences are very small, we will always present $\theta$ and $\gamma_{n}$ rather than $T$ and $\sigma_{\theta}$ distributions. Potential temperature is the proper variable when considering adiabatic motions while neutral density is the most accurate one to examine budgets of water mass and other properties.

\section{Methodology to estimate vertical velocities}

Vertical velocity may be expressed as the addition of three components: the motion associated with the rising/lowering of isopycnals, epipycnal (along-isopycnals) motion and diapycnal motion. The first two components imply no mass transfer between isopycnal layers. Here we use the simplest possible approach to evaluate these components: we assume that the rising/lowering of isopycnals and epipycnal vertical motion result from ageostrophic motions that tend to restore departures from geostrophic balance and may be diagnosed through the adiabatic QG theory, and Ekman transports in the upper mixed-layer which arise entirely from wind-induced forcing. Diapycnal velocities, on the other hand, will be estimated by adjusting the water balances in isopycnal layers: any imbalance has to be satisfied through transfer from one layer to another.

\subsection{Quasi-geostrophic mesoscale vertical velocities}

Vertical velocities associated to mesoscale structures can be inferred by solving the Q-vector form of the omega equation. For this purpose we partition the velocity field into geostrophic and ageostrophic components $\vec{v}=(u, v, w)=$ $\left(u_{g}, v_{g}, 0\right)+\left(u_{a}, v_{a}, w_{q g}\right)$ and define the Rossby number as the normalized relative 
vorticity field, $\zeta / f \equiv(\partial v / \partial x-\partial u / \partial y) / f$, where $f=2 \Omega \sin \phi$ is the planetary vorticity, with $\Omega$ the Earth's angular velocity and $\phi$ the latitude; we take $\phi$ as constant and equal to the mean latitude of our study area so that $f$ is also constant.

Assuming the Rossby number is small $(R o \ll 1)$, we may approximate the rate of change following a particle as $D_{g} / D t=\partial / \partial t+u_{g}(\partial / \partial x)+v_{g}(\partial / \partial y)$. Thus, the QG momentum equations may be written as

$$
\begin{aligned}
& \frac{D_{g} u_{g}}{D t}-f v_{a}=0 \\
& \frac{D_{g} v_{g}}{D t}+f u_{a}=0
\end{aligned}
$$

The mass conservation for an incompressible flow is

$$
\frac{D_{g} \rho}{D t}+w_{q z} \frac{\partial \rho}{\partial z}=0
$$

where $\rho$ is the water density. Under the hydrostatic approximation $(\partial p / \partial z=-\rho g$, where $p$ is pressure and $g$ is the gravity acceleration) equation (3) becomes

$$
\frac{1}{\rho_{0}} \frac{D_{g}}{D t} \frac{\partial p}{\partial z}+N^{2} w_{q g}=0
$$

where $N^{2}=(-g / \rho) \partial \rho / \partial z$ is the squared buoyancy frequency and $\rho_{0}$ is the mean density.

Using the geostrophic relations $\left(f u_{g}=\left(-1 / \rho_{0}\right) \partial p / \partial y\right.$ and $\left.f v_{g}=\left(1 / \rho_{0}\right) \partial p / \partial x\right)$ to eliminate the time derivatives between (1), (2) and, (4) we obtain

$$
\begin{aligned}
& \frac{\partial}{\partial x}\left(N^{2} w_{q g}\right)-f^{2} \frac{\partial u_{a}}{\partial z}=Q_{x} \\
& \frac{\partial}{\partial y}\left(N^{2} w_{q g}\right)-f^{2} \frac{\partial v_{a}}{\partial z}=Q_{y}
\end{aligned}
$$


where $Q_{x}$ and $Q_{y}$ are the horizontal components of the QG Q-vector $(\vec{Q})$ given by

$$
\vec{Q}=\left(Q_{x}, Q_{y}\right)=2 \frac{g}{\rho_{0}}\left(\frac{\partial \overrightarrow{u_{g}}}{\partial x} \cdot \vec{\nabla}_{h} \rho, \frac{\partial \vec{u}_{g}}{\partial y} \cdot \vec{\nabla}_{h} \rho\right)
$$

and $\nabla_{h}=(\partial / \partial x, \partial / \partial y, 0)$ is the horizontal gradient operator. Finally, using the continuity equation to eliminate the horizontal ageostrophic velocities yields

$$
\nabla_{h}^{2}\left(N^{2} w_{q g}\right)+f^{2} \frac{\partial^{2} w_{q g}}{\partial z^{2}}=\vec{\nabla}_{h} \cdot \vec{Q}
$$

This 3D elliptic equation for $w_{q g}$ is known as the Q-vector formulation of the QG omega equation (Hoskins et al., 1978) and it can be solved provided that appropriate boundary conditions are specified and the forcing at every grid point of the domain is known. The forcing term is the horizontal divergence of the $\vec{Q}$ which may be determined from the density and geostrophic velocity fields.

Regarding boundary conditions, $w_{q g}$ is usually set equal to 0 (Dirichlet conditions) at the upper and lower boundaries of the domain, here taken to be the sea surface and $500 \mathrm{db}$. Near the sea surface $w_{q g}$ does not have to be exactly zero. Instead, this vertical velocity should match some externally provided condition, such as arising from wind-induced convergence/divergence in the surface mixed-layer. At the sea surface $w_{q g}$ turns out to be substantially smaller than the $w_{q g}$ values attained at depth, and is therefore safely approximated to zero. At the lower boundary the choice $w_{q g}=0$ implies that mesoscale motions there are very much reduced, which is supported by the relatively small $\theta$ and $S$ vertical displacements observed near $500 \mathrm{db}$ (Section 4.2).

Lateral boundary conditions are usually set in a more arbitrary way, here we also use Dirichlet conditions at all boundaries. It may be shown that, provided the 
horizontal scale of the structures is smaller than the size of the domain, the ellipticity of equation (8) causes the interior solution for $w_{q g}$ to be relatively insensitive to the imposed conditions (see for instance Gomis and Pedder, 2005). Setting Neumann conditions at the lateral boundaries, $w_{q g}$ differences reached only $10 \%$ a few grid points away from the boundary.

\subsection{Wind-induced and diapycnal vertical velocities}

Wind-driven vertical motions may be induced by two processes that depend on the sea-surface horizontal wind-stress vector: Ekman pumping and normal-toshore Ekman transport (e.g. Pickett and Paduan, 2003). The sea-surface horizontal wind-stress vector is defined as $\vec{\tau}=\left(\tau_{x}, \tau_{y}, 0\right)$, with east-west $\left(\tau_{x}\right)$ and north-south $\left(\tau_{y}\right)$ components. This vector field is inferred from the wind fields using empirical algorithms (e.g. Liu and Tang, 1996). In the open ocean there are two potentially relevant contributions for Ekman pumping: the first one results from the convergence/divergence generated in the surface-mixed layer by the wind stress curl (linear Ekman pumping) and second one arises from the interaction between the wind stress and the background geostrophic relative vorticity (non-linear Ekman pumping) (Stern, 1965).

The linear Ekman pumping velocities are calculated as

$$
w_{e k}=\frac{1}{\rho_{0}\left(f+\zeta_{0}\right)} \vec{k} \cdot\left(\nabla_{h} \times \vec{\tau}\right)
$$

where $\nabla_{h} \times \vec{\tau}$ is the curl of the mean wind stress during the cruise period and can be derived by applying finite differences to the QuikSCAT wind stress field. The 
non linear Ekman pumping velocities are computed as follows

$$
w_{\text {nle }}=\frac{\vec{\tau} \times \vec{k}}{\rho_{0}\left(f+\zeta_{0}\right)^{2}} \cdot \nabla_{h}\left(f+\zeta_{0}\right)
$$

where $\zeta_{0}$ is the geostrophic relative vorticity at the sea surface.

Nearshore, however, the presence of the coast makes Ekman coastal divergence to be the relevant contribution to vertical motion. In order to estimate the associated vertical velocities, the offshore component of Ekman transport at each grid point is computed from the cruise mean wind stress vector closest to the coast (roughly $30 \mathrm{~km}$ offshore). The normal-to-shore Ekman transport per unit length is hence given by $U=\tau_{p} /\left(\rho_{0} f\right)$, where $\tau_{p}$ is the wind stress component parallel to coast. To obtain the upwelling vertical velocity $w_{u p}$ we also need the width of the area where the coastal constraint applies, $L_{x}$, so that $w_{u p}=U / L_{x}$. Here we set $L_{x}$ equal to the width of the observed upwelling area, calculated as the mean distance between the $200 \mathrm{~m}$ isobath and the frontal region (as defined through selected dynamic-height contours at $20 \mathrm{db}$, see Section 4.2). This turns out to be of the order of $100 \mathrm{~km}$.

The cross-shore extent of the upwelling area may be compared with the width of the frontal system as estimated through the internal Rossby radius of deformation for an idealized two-layer upwelling system. This is given by $\left(g^{\prime} h\right)^{1 / 2} / f$, where $h$ is the thickness of the upper layer and $g^{\prime}=g\left(\rho_{2}-\rho_{1}\right) / \rho_{1}$, with $\rho_{1}$ and $\rho_{2}$ being the densities of the upper and lower layers. Using $\rho_{2}-\rho_{1}=0.3 \mathrm{~kg} \mathrm{~m}^{-3}$ and $h=150 \mathrm{~m}$ as typical values for the region (see Section 4.3) we obtain this two-layer Rossby radius to be about $10 \mathrm{~km}$, one order of magnitude less than the width of the upwelling area. 
Finally, vertical velocities also result from turbulent mixing. In a stratified fluid the presence of positive vertical velocities implies transformation of kinetic into potential energy. This is possible in critically stable regions, with sufficiently large vertical shear, which frequently occur within frontal systems in upwelling regions (Kundu and Beardsley, 1991; Pelegrí and Richman, 1993). These vertical velocities are often parameterized in terms of the gradient Richardson number, with a large degree of uncertainty. Here we use a much simpler approximation, based on the fact that the geostrophic flow is non-divergent. We calculate the geostrophic field using $500 \mathrm{db}$ as an appropriate reference level for the region south of the Canary Islands (Olbers et al., 1985; Machín et al., 2006a; Pelegrí et al., 2006; Pastor et al., 2008), with a small reference velocity to guarantee that the deep layers are non-divergent. A geostrophic mass imbalance in the surface layers is hence viewed as the result of horizontal convergence/divergence that has to be supplied by the neighbouring layers via diapycnal velocities $w_{d i a}$. This concept is useful in assessing water exchange between adjacent layers in idealized box-type models, as discussed below.

\section{Distribution and transport of properties}

\subsection{Horizontal structure}

Figure 3 displays the SST and surface Chl-a fields on March 29 and April 7, respectively, obtained from the AVHRR and SeaWIFS sensors. The insets show how the far-field is characterized by relatively warm and unproductive offshore waters, in contrast with the cool and productive waters of the CTZ that occupy 
a band of about $100 \mathrm{~km}$ from the coastline. The main images illustrate our region of interest, south of the eastern islands. This mesoscale picture bears a great similarity to that depicted by Barton et al. (2004) for essentially the same region in August 1999. It is characterized by the existence of filaments stretching from the coastal region and a remarkable mesoscale activity reflected in both SST and Chl-a fields. Two filaments (F1 and F2) appear as offshore extensions of cold and productive water attached to the shelf break near Capes Bojador and Juby. Barton et al. (2004) pointed to the relation between F1 and a quasi-permanent cyclonic eddy trapped in the trough south of the inner islands, as well as between F2 and an intermittent anticiclonic eddy southeast of Fuerteventura island, to form systems that favour the exchange between the continental shelf and open ocean waters. Between F1 and F2 we may identify the A1-C1 eddy dipole which leads to onshore flow in between (Figure 3a) .

Figure 4 shows the circulation and water properties distribution at $20 \mathrm{db}$. The dominant signature is the baroclinic coastal upwelling jet entering the region through the northeastern margin (Figure 4a) and meandering southwestwards to the southern end of the domain where it loses strength and turns southeast. The largest geostrophic velocities $\left(0.18 \mathrm{~m} \mathrm{~s}^{-1}\right)$ are related to the sharper horizontal gradients in dynamic height at $20 \mathrm{db}$ referenced to $500 \mathrm{db}, D_{20 / 500}$. In Figure $4 \mathrm{a}$ we show these to be bound by the 0.625 and 0.64 dyn $\mathrm{m}$ isolines (thick dashed lines), located approximately $100 \mathrm{~km}$ off the African coast. These velocity values are in agreement with wintertime observations and inverse model results for the flow along the passage east of Lanzarote Island (Machín et al., 2006a). 
The property distributions are consistent with the classical two-dimensional (2D) vertical upwelling cell (e.g. Gill and Clarke, 1974). A shelf-break front roughly follows the $200 \mathrm{~m}$ isobath and separates relatively dense (cold and fresh) and pigment-enriched waters, adjacent to the African coast, from the offshore region (Figures 4b,c). A southward along-slope jet, which brings relatively cold and fresh waters of northern origin, is associated with this front. The maximum cross-frontal horizontal gradients are found to the north, where $\theta$ and $S$ decrease about $1.4{ }^{\circ} \mathrm{C}$ and 0.12 over a distance of $50 \mathrm{~km}$.

Figure $5 \mathrm{a}$ and $\mathrm{b}$ shows the dynamic height and the corresponding $\overrightarrow{v_{g}}$ fields at $50,110,245$ and $410 \mathrm{db}$ (relative to $500 \mathrm{db}$ ), together with the $\theta$ and fluorescence fields. The $S$ fields are not shown since they have very similar patterns to the $\theta$ fields, as expected from the very tight $\theta$-S relation in surface and central waters (Figure 6, see next subsection). A relatively cold and fresh surface tongue extends west of Cape Juby, along $27.8^{\circ} \mathrm{N}$ until the southwestern tip of Fuerteventura Island $\left(14.5^{\circ} \mathrm{W}\right)$ from where it stretches south (Figures $3 \mathrm{a}$ and $\left.4 \mathrm{~b}, \mathrm{c}\right)$. This surface feature is a shallow filament, as it fades out by $50 \mathrm{db}$ (Figure $5 \mathrm{~b}$ ). The high cross-jet $\theta$ gradients are maintained with depth, depicting an intense frontal system that reaches down to at least $245 \mathrm{db}$ and marks the real boundary between coastal upwelled and offshore waters.

The geostrophic circulation pattern follows the position of the near-surface (20 db) jet (Figure 4a), which persists invariant down to $245 \mathrm{db}$ (Figure 5a). The jet itself is linked to the frontal system, as is apparent from the 110 and $245 \mathrm{db} \theta$ fields, flowing roughly parallel to the slope. The jet and all eddies have similar speeds 
down to $110 \mathrm{db}$. At $245 \mathrm{db}$ we still find intense currents along the jet axis and in the cyclonic and anticyclonic eddies located between Fuerteventura and Gran Canaria, while some of those eddies east of the jet become relatively weak. At 410 $\mathrm{db}$ the jet weakens but there are still appreciable flows around the Fuerteventura and Gran Canaria eddies.

The distribution of in situ fluorescence at $20 \mathrm{db}$ (Figure 4b) shows maximum values over the continental platform, in concordance with the cold and highpigment platform waters visible in the remote sensing images (Figure 3). Figure $5 \mathrm{~b}$ displays the in situ fluorescence distributions at 50,110, 245 and $410 \mathrm{db}$, with significant differences when compared to the $20 \mathrm{db}$ field. At $50 \mathrm{db}$ the maximum values $(>1.2 \mathrm{~V})$ do not correspond to shelf waters $(<0.8 \mathrm{~V})$, rather they have a patchy distribution located on a band along the upwelling coastal front, immediately offshore the $17.4{ }^{\circ} \mathrm{C}$ isotherm. At $110 \mathrm{db}$ the maximum values are found further offshore but the distribution remains patchy, pointing at the possibility of localized downwelling linked to some phases of eddies and meanders in the region. This point will be re-examined in Section 5.3. Further deep, at 245 and 410 $\mathrm{db}$, the fluorescence values are much smaller, likely not significant.

Figure 5c illustrates the geostrophic Rossby number, defined as $R o=\zeta_{g} / f$, superimpossed on the SST image of March 29 (Figure 3). It ranges from -0.3 to 0.3 at surface and weakens slowly with depth. Relative Ro maxima and minima are associated with cyclonic and anticyclonic structures, with length scales no more than a few tens of kilometes, of the same order of magnitude as the Rossby deformation radius. The zero Ro line roughly defines a streamline for the jet core, 
as well as the edges of mesoscale eddies.

Although QG theory may only strictly be used when $R o<<1$, several studies on the applicability of this theory have shown that the relative errors of directly derived quantities (such as $\overrightarrow{v_{g}}$ and $\zeta_{g}$ ) are of the same order as Ro (Shearman et al., 1999; Gomis et al., 2001). Hence, for our study we expect these errors to not exceed $30 \%$, typically much less away from the center of eddies. However, as the mesoscale vertical velocity field $w_{q g}$ depends on the non-linear combinations of the second derivatives of density and geostrophic velocity, it is difficult to assess what the associated errors would be. These relative errors are likely of the same order as the maximum Ro values, important but possibly no much larger than other errors inherent to the horizontal grid resolution and the survey's lack of sinopticity (Gomis and Pedder, 2005). We may therefore trust the $w_{q g}$ fields but with some caution, only accepting the calculated spatial patterns and gross numbers.

\subsection{Vertical structure}

The $\theta$-S diagram shows the presence of NACW as the principal water mass in the sampled depth range (Figure 6). NACW is identified by a linear $\theta$-S relationship, from near-surface waters down to the isoneutral $\gamma_{n} \approx 27.38 \mathrm{~kg} \mathrm{~m}^{-3}$ (roughly $700 \mathrm{db}$, Hernández-Guerra et al., 2005), therefore completely covering the upper $500 \mathrm{db}$ of the ocean as shown in Figure 6. Since the cruise was done during late winter, when the atmosphere-ocean heat flux has just began to increase (e.g. Hsiung, 1986), the offshore waters hardly show a seasonal thermocline. Nevertheless the $\theta-\mathrm{S}$ scattering in the upper layers reflects the differences between the nearslope upwelled waters, which are central waters that have recently reached the sea 
surface, and the offshore surface waters, which have been close to the surface long enough to be modified through air-sea interaction.

In order to sort out the surface water types, on the $\theta$-S diagram we have superimposed three mean $\theta-\mathrm{S}$ curves constructed by clustering the stations as a function of their $D_{20 / 500}$ values (see Figure 4a). The ranges $D_{20 / 500} \leq 0.625$, $0.625 \leq D_{20 / 500} \leq 0.64$ and $D_{20 / 500} \geq 0.64$ have been chosen to represent the upwelled, frontal and open-ocean waters, respectively. With this division the mean curves become well differentiated and the three $\theta$-S domains, defined by data points within one standard deviation of these mean curves, hardly overlap. Below this surface layer, the three curves are indistinguishable and correspond to the eastern NACW. This unique relation between $\theta$ and $S$ is what, for the permanent upper-thermocline, allows a direct inference of the $S$ from $\theta$ data (e.g. it allows to infer the $S$ distributions from the middle panels in Figure 5).

Figure 7 shows vertical sections of $\gamma_{n}$, the meridional geostrophic velocity $v_{g}$, $\theta$ and fluorescence along $27.95^{\circ} \mathrm{N}, 27.55^{\circ} \mathrm{N}$ and $27.25^{\circ} \mathrm{N}$. Geostrophic velocities, relative to $500 \mathrm{db}$, reveal the close association between the front and the jet current. A southward baroclinic jet flows separated from the coast, over a region of rising isoneutrals. Maximum jet velocities of $0.18 \mathrm{~m} \mathrm{~s}^{-1}$ are observed at surface, decreasing to $0.05 \mathrm{~m} \mathrm{~s}^{-1}$ at $300 \mathrm{db}$. This confirms that the largest baroclinic fraction of the jet is confined to the upper layers, i.e. the surface geostrophic velocities would not change much if we had chosen a reference level at $400 \mathrm{db}$. East of this front the isoneutrals dip against the continental slope, inducing a poleward undercurrent, its core located at about $\gamma_{n}=26.8 \mathrm{~kg} \mathrm{~m}^{-3}$ (Figure 7c). In the southern 
section $\left(27.25^{\circ} \mathrm{N}\right)$ the southward jet actually appears to split around the poleward undercurrent (see also the $\overrightarrow{g_{g}}$ field at $245 \mathrm{db}$ in Figure 5a). Cross-shore geostrophic velocities are generally weak, well within the $\pm 0.1 \mathrm{~m} \mathrm{~s}^{-1}$ range.

Lifting of isotherms, isohalines and isoneutrals is noticeable within $100 \mathrm{~km}$ from the coast, influencing approximately the top $300 \mathrm{db}$ of the water column (Figure 7). For example, the $17{ }^{\circ} \mathrm{C}$ isotherm is lifted by approximately $150 \mathrm{db}$ over $100 \mathrm{~km}$ at 27.55 and $27.95^{\circ} \mathrm{N}$ (Figures $7 \mathrm{a}, \mathrm{b}$ ) giving an average isotherm slope of

about $1.5 \times 10^{-3} \mathrm{db} \mathrm{km}^{-1}$. The correspondence between the $17.4{ }^{\circ} \mathrm{C}$ isotherm and the deep fluorescence maximum (DFM) layer, located at the top of the nutricline (Tett et al., 2002), is remarkable (Figure 7).

\subsection{Water transports}

We have calculated the mass transports entering or leaving the domain by simply integrating the velocity through each outer section of the grid, i.e. across each outer section and from $500 \mathrm{db}$, or the sea floor if shallower, to the sea surface. A surface mixed layer depth ranging from 12 to $76 \mathrm{~m}$ is obtained by following the procedure proposed by Kara et al. (2000). Thus, the water column is divided into three layers by isoneutrals $26.65,26.85$ and $27.162 \mathrm{~kg} \mathrm{~m}^{-3}$. These layers are identical to those proposed by Ganachaud (2003) for the North Atlantic Ocean except for the first one, here selected denser in order to match the maximum observed mixed-layer depth $(76 \mathrm{~m})$ and thus to contain all the wind-induced Ekman transports (see below). The middle layer reaches down to about $15^{\circ} \mathrm{C}$, near $300 \mathrm{db}$ far offshore, so it includes most of the water column that upwells towards the coast. The deep layer goes down to about $11.5^{\circ} \mathrm{C}$, near the $500 \mathrm{db}$ level. This deep layer 
is essentially unaltered by the vertical motions; it is far from the direct influence of the wind and has relatively weak currents, therefore it should not experience substantial mixing with the overlying layer. Figure 7 is useful to visualize the density (left panels) and thermal (right panels) structure of the water column down to 500 $\mathrm{db}$.

Ekman transports are computed from the relations $T_{E x}=\tau_{y} /\left(\rho_{0} f\right)$ and $T_{E y}=-$ $\tau_{x} /\left(\rho_{0} f\right)$, where $\tau_{x}$ and $\tau_{y}$ are the zonal and meridional mean wind stress during the cruise period as determined from QuikSCAT. $T_{E}$ amounts to $0.07,-0.12$ and $0.11 \mathrm{~Sv}$ for the northern, western and southern sections, respectively $\left(1 \mathrm{~Sv}=10^{6}\right.$ $\mathrm{m}^{3} \mathrm{~s}^{-1} \sim 10^{9} \mathrm{~kg} \mathrm{~s}^{-1}$ ). These transports are assumed to exclusively take place in the surface layer. Further, the water transports in the deepest layer are impossed to balance out by assuming a barotropic velocity of $-2.3 \times 10^{-3} \mathrm{~m} \mathrm{~s}^{-1}$ at the northern section. Such a small negative reference velocity is coherent with inverse model results obtained for the passage east of Lanzarote island by Machín et al. (2006a). These authors found an annual-mean reference velocity close to $-0.01 \mathrm{~m} \mathrm{~s}^{-1}$ at about $800 \mathrm{db}$, but with substantial temporal variability.

Figure 8a shows the layer integrated mass transport in each section. Adding the transports in all three layers $(0.34,0.57$ and $0.27 \mathrm{~Sv}$ through the upper, middle and deep layers, respectively) gives a total of $1.18 \mathrm{~Sv}$ flowing through the north section, with about $1.0 \mathrm{~Sv}$ corresponding to the transport of NACW by the CUC between the islands and the African coast. This result is in good agreement with the mean transport through this passage as determined from expandable bathythermograph (XBT) and CTD casts (Hernández-Guerra et al., 2001, 2002; Knoll et al., 
2002). It also agrees with the transport in the top $600 \mathrm{~m}$ as estimated from an eastern boundary mooring located in the middle of the channel between the eastern Canary Islands and the African continental slope (Hernández-Guerra et al., 2003). A recent estimate based on 10 years of current-meter data from this passage shows a mean value close to our result but with rather large variability, $-0.81 \pm 1.48 \mathrm{~Sv}$ (Fraile-Nuez et al., 2010).

Off NW Africa the background upper-thermocline boundary current is the CC, embracing the whole Canary Archipelago and beyond (approximately $1000 \mathrm{~km}$ ), with a transport of order $5 \mathrm{~Sv}$ within 700 db of NACW (Käse et al., 1985, 1986; Stramma and Siedler, 1988). An important fraction of its transport occurs close to the continental slope, as the CUC, linked to the coastal upwelling frontal system (Pelegrí et al., 2005a; Pelegrí et al., 2005b; Machín et al., 2006a). Figure 8b shows the southward transport across $27.7^{\circ} \mathrm{N}$, with a maximum increase over the frontal region. This figure ilustrates the presence of significant southward transport both over the upwelling region (about $0.5 \mathrm{~Sv}$ of barotropic contribution) and over the frontal system itself (about $1 \mathrm{~Sv}$ of baroclinic contribution), beyond which the transport increases more slowly as the CUC merges with the offshore CC.

\subsection{Vertical velocity fields}

The $1.18 \mathrm{~Sv}$ input through the north section is approximately balanced by 1.36 Sv leaving the box through the west section $(0.99 \mathrm{~Sv}$ distributed as $0.37,0.34$ and $0.28 \mathrm{~Sv}$ for the upper, middle and deep layers, respectively) and, to a lesser extend, through the south section $(0.37 \mathrm{~Sv}$ distributed as $0.20,0.19$ and $-0.02 \mathrm{~Sv}$ for the upper, middle and deep layers, respectively) (Figure 8a). The net mass imbalance, 
$0.18 \mathrm{~Sv}$, mainly reflects flow convergence in the middle layer and divergence in the top one. This result implies diapycnal transfer from the middle into the surface layer, as expected to occur in upwelling regions (Pelegrí and Richman, 1993). If we assume that most of this transfer occurs in the frontal region, about $30 \mathrm{~km}$ wide and $100 \mathrm{~km}$ long, then it implies a diapycnal velocity $w_{d i a}=6 \times 10^{-5} \mathrm{~m} \mathrm{~s}^{-1}$ [5.2 $\left.\mathrm{m} \mathrm{day}^{-1}\right]$. We may expect that maximum diapycnal velocities will be much greater than this average value, as a response to subcritical stages of the baroclinic upwelling jet (Kundu and Beardsley, 1991; Pelegrí and Richman, 1993).

The vertical velocities within the upwelling region are controlled by the coastal constraint, which induces a 2D vertical cell along a normal-to-shore section. The Ekman transport parallel to the coast is estimated to be about $0.08 \mathrm{~Sv}$. Divided by the upwelling area (100 km width and the length of our coastline) gives an upwelling velocity of $w_{u p}=0.8 \times 10^{-5} \mathrm{~m} \mathrm{~s}^{-1}\left[0.7 \mathrm{~m} \mathrm{day}^{-1}\right]$. As a first approximation this velocity should affect the whole width of the upwelling region and down to the $15{ }^{\circ} \mathrm{C}$ isotherm. Note that in a stratified surface ocean a fraction of upwelling could reach the sea surface as a diapycnal flow; another fraction, however, may actually rise in the less stratified near-slope region remaining its original density (i.e. as an epipycnal transfer) before warming and moving offshore as a result of Ekman transport. In this study we have no way to differentiate between these two contributions so sea-surface Ekman divergence related to the coastal constraint is simply named upwelling velocity.

The linear Ekman pumping velocity calculated for each point of the domain leads to a mean negative $w_{e k}$ of $-0.3 \times 10^{-5} \mathrm{~m} \mathrm{~s}^{-1}\left[-0.26 \mathrm{~m} \mathrm{day}^{-1}\right]$. This value, 
despite being small, is consistent with negative Ekman pumping values that must occur within the subtropical gyre (e.g. Leetma and Bunker, 1978). Integrated over the whole domain this corresponds to a downward transport of $-0.05 \mathrm{~Sv}$, of the same order as the coastal Ekman transport but of opposite sign. Non-linear Ekman velocities $w_{n l e}$ may locally be as much as 10 times larger than its linear counterpart. However, it has intermittent positive and negative values, associated to the mesoscale field, so that its integrated vertical transport is indistinguishable from zero $(<0.01 \mathrm{~Sv})$.

Superposed on the background vertical flow there are relatively large localized $w_{q g}$ values, with a patchy structure associated to the cyclonic and anticyclonic features located to both sides of the frontal region (Figures 9 and 10). The $w_{q g}$ field changes slowly with depth within the frontal region, with maximum velocities (of order $10 \mathrm{~m} \mathrm{day}^{-1}$ ) occurring between 100 and $150 \mathrm{db}$. Furthermore, it has much smaller length scales than the $\zeta_{g}$ field, being linked to certain phases of the meanders and eddies. However, the $w_{q g}$ field is so patchy that its associated net transport at any depth is estimated to be of order $0.01 \mathrm{~Sv}$.

In summary, the $w_{d i a}$ is relatively large (about $5 \mathrm{~m} \mathrm{day}^{-1}$ ) but occurs in a relatively narrow frontal region therefore contributing to a moderate transport of about $0.18 \mathrm{~Sv}$. The offshore linear Ekman pumping is $-0.05 \mathrm{~Sv}$ and, as it occurs over the whole domain, leads to small vertical velocities $w_{e k}$ of about $-0.3 \mathrm{~m} \mathrm{day}^{-1}$; contrary to $w_{n l e}$ which reach velocities 10 times larger and its transport is negligible. The coastal Ekman divergence is about $0.08 \mathrm{~Sv}$ and leads to vertical velocities $w_{u p}$ of about $1 \mathrm{~m} \mathrm{day}^{-1}$ over the upwelling region. In our region, transports due 
to either coastal Ekman divergence or offshore linear Ekman pumping are small but their joint effect is even smaller. Finally, the $w_{q g}$ peak values (Figures 9 and 10) are much larger than either $w_{u p}$ or $w_{e k}$ and even larger than $w_{d i a}$, i.e. order $10 \mathrm{~m} \mathrm{day}^{-1}$ instead of order 0.1 to $1 \mathrm{~m} \mathrm{day}^{-1}$, but their patchiness leads to a very small transport of order $0.01 \mathrm{~Sv}$.

\section{Discussion}

\subsection{The upwelling, frontal and offshore regions}

Off NW Africa, sustained equatorward trade winds drive offshore Ekman transport in the surface layer, leading to the upwelling of cold, fresh and nutrient-rich subsurface waters. The result is the formation of a frontal system with isopycnals outcropping near-shore, a baroclinic system over which a relatively shallow upwelling jet flows along-shore. A near steady-state system, with constant intensity jet and outcropping isopycnals at some offshore distance, is eventually possible because of the along-shore resistance of the lower layers (in the form of bottom and lateral surface stresses, e.g. Csanady and Pelegrí, 1995) and as offshore Ekman transport is maintained via cross-shore vertical motions, both along (epipycnal) and across (diapycnal) the upwelling isopycnals.

The frontal system is the dominating baroclinic structure in the CTZ. It is a relatively narrow and shallow feature, typically about $30 \mathrm{~km}$ wide and some 250-300 m deep (Pelegrí et al., 2005a; Pelegrí et al., 2005b; Pastor et al., 2008), which divides the CTZ in three regions: upwelled waters, frontal region and offshore ocean. The upwelled waters may be idealized as a near-homogeneous water 
columm that reaches all the way from the sea surface to the sea bottom. The motion of this deep water column represents a near-barotropic transport, a contribution with relatively large inertia that slowly changes its momentum through the large-scale wind regime. This barotropic water transport attains significant values because of the large water depth, despite the presence of relatively small horizontal velocities. The frontal waters, on the other hand, reach much larger horizontal velocities but they go to near-zero at the base of the frontal system (left panels in Figure 7). Hence, this baroclinic contribution has much less inertia than its barotropic counterpart. Its transport depends on intermittent events (of the order of several days to a few weeks) that cause the intensification/weakening of upwelling and, consequently, the acceleration/slowing down of the current associated with the frontal upwelling system. The different character of both contributions has been discussed by Pelegrí and Richman (1993).

The above idealized 2D picture is modified by many factors, such as alongshore changes in wind/bathymetry and the interaction with eastern boundary currents (either the $\mathrm{CC}$ or the poleward undercurrent). There are also numerous instabilities, in the form of meanders, filaments and eddies, generated at the front itself or by the blockage effect of the islands to the current (Machín and Pelegrí, 2006b), which may form an intense mesoscale eddy field (Arístegui et al., 1994). All these factors are responsible for the existence of significant spatial variability, with localized regions of intense vertical motions, as discussed next.

The satellite images in Figure 3 illustrate the presence of the upwelling region adjacent to the coast, characterized by very cold and productive waters. The 
coldest and most productive waters are actually located over the platform, but its influence extends well beyond the $200 \mathrm{~m}$ isobath (e.g. Figure 3). From these images, as well as from the horizontal sections in Figure 5, we may locate the offshore extreme of the upwelling region as the $17.4{ }^{\circ} \mathrm{C}$ isotherm at $110 \mathrm{db}$, approximately $100 \mathrm{~km}$ off the African continental slope.

The distribution of $\gamma_{n}, \overrightarrow{v_{g}}$ (relative to $500 \mathrm{db}$ ) and $\theta$ in three sections normal to shore $\left(27.95^{\circ} \mathrm{N}, 27.55^{\circ} \mathrm{N}\right.$ and $\left.27.25^{\circ} \mathrm{N}\right)$ is very informative (Figure 7). In the upwelling region the upper isotherms (down to about $16{ }^{\circ} \mathrm{C}$ ) rise towards the sea surface. Further deep the isopycnals downwell towards the slope in what constitutes the core of the poleward undercurrent. At $27.95^{\circ} \mathrm{N}$ the poleward undercurrent is adjacent to the platform but further south it appears to flow above a deeper slope isobath. At $27.55^{\circ} \mathrm{N}$ a near-barotropic southward flow of about $0.06 \mathrm{~m} \mathrm{~s}^{-1}$ occupies the water column onshore from this undercurrent. At $27.25^{\circ} \mathrm{N}$ an anticyclone (also visible in Figure 3) appears as the dominant feature adjacent to the slope.

From the vertical sections in Figure 7 and 9 we may appreciate that the width of the frontal system is about $30 \mathrm{~km}$. Most isoneutrals in the frontal system do not reach the surface, and their largest horizontal gradients occur at near-surface levels, typically at about $50 \mathrm{db}$. In some instances, however, these large gradients are found at deeper levels, e.g. near $200 \mathrm{db}$ along $27.55^{\circ} \mathrm{N}$ (Figure $7 \mathrm{~b}$ ). The baroclinic jet is associated to this front, its main baroclinicity reaching down to some $300 \mathrm{db}$. This jet is most intense at $27.55^{\circ} \mathrm{N}$ with maximum values of $0.18 \mathrm{~m} \mathrm{~s}^{-1}$ and least intense at $27.25^{\circ} \mathrm{N}$ where it only reaches $0.10 \mathrm{~m} \mathrm{~s}^{-1}$, apparently because of the nearshore anticyclone which also displaces the jet offshore. 
As a first approximation the zero $\zeta_{g}$ lines should give an idea of the extension of the frontal region and the beginning of the offshore region. The offshore region would be located seaward from the frontal system, where the baroclinicity has substantially decreased and $\zeta_{g}$ goes to zero. The zero $\zeta_{g}$ lines in Figure 10 define a wide frontal system, apparently squeezing the offshore region to a minimum expression southwest of Fuerteventura Island.

In the absence of mesoscale features we would anticipate the offshore region to display a relatively weak southward flow, the Canary Current, reflected by the isoneutrals rising gently towards the coast. However, this background situation is completely masked by the presence of mesoscale features. Because of these features, a second zero $\zeta_{g}$ line intrudes far west of the jet core zero contour. Figure 10 underscores the predominance of mesoscale features in our region of interest, which cause offshore $\zeta_{g}$ values as large as those found in the other two regions.

Figures 9 and 10 indeed illustrate the presence of several mesoscale structures, particularly eddies near the islands, with large QG mesoscale vertical velocities. In the anticyclonic structure attached south of Fuerteventura Island there is a dominance of downwelling (negative) $w_{q g}$. In the other vortices, located further away from the islands, there are alternating areas, or phases, with positive and negative values. This agrees with the idea that young eddies, i.e. shortly after their generation by the islands, are still undergoing vertical adjustment, so that cyclones/anticyclones must have predominant positive/negative vertical velocities (Sangrà et al., 2007). However, once the vortices reach QG equilibrium then verti- 
cal motions of both signs appear in both cyclones and anticyclones. These maxima are located on the edges of eddies, as a result of the convergence/divergence of $\vec{Q}$ (Bower, 1989; Gomis et al., 2001).

\subsection{Origin of mesoscale structures}

The important mesoscale activity south of the Canary Islands has been traditionally ascribed to their topographic blocking of the southward CC (Arístegui et al., 1994, 1997; Barton et al., 1998, 2004; Sangrà et al., 2005; Sangrà et al., 2007, 2009). Jiménez et al. (2008) have found that this topographic mechanism may be supported through wind-driven Ekman pumping at the islands' wakes. However, the nearby presence of the frontal system raises the possibility that some eddies may arise from instabilities of the associated baroclinic jet.

In order to elucidate the origin of the observed eddies, we examine the vertical distributions of $\theta$ along two different transects which cross two anticycloniccyclonic eddy pairs, or dipoles, located in the offshore (Dipole 1) and upwelling (Dipole 2) regions (Figures 11a,b). Note Dipole 2 is formed by the $\mathrm{C} 1$ feature in Figure 3 and an anticyclone found further northeast, not visible in the SST image. The number of mesoscale structures is abundant (e.g. Figures 10 and 11a) and many other combinations are certainly possible. However, based on the sections in Figures 7 and 9, we have selected these two dipoles as representative of what we identify as two different types of eddies: deep barotropic (Dipole 1) versus shallow baroclinic (Dipole 2). The paths shown in Figure 11a follow the grid points that best cross the center of these eddies. 
The two dipoles have significantly distinct thermal patterns, which are most evident in the $\theta$ differences between the adjacent eddy cores as displayed in the right-hand-side of these figures. The isotherms in Dipole 1 have near-constant slope down to about $400 \mathrm{db}$, suggesting a dominance of the barotropic component; therefore, they are indicative of island-generated eddies. Contrary, Dipole 2 exhibits substantial flattening of isotherms below $250 \mathrm{db}$, thus its generation is apparently associated to baroclinic instabilities at the upwelling front. If we were to examine the dipole formed by the $\mathrm{C} 1$ and $\mathrm{A} 1$ features in Figure 3 we would have found it to be of mixed type, as A1 also has isotherms with significant slopes until near the bottom of the sampled water column (see Figures 7a and 9a, along $\left.27.25^{\circ} \mathrm{N}\right)$.

These differences are also clear in the velocity distribution through the two dipoles (Figures 11a,c,d). Dipole 1 exhibits a $\overrightarrow{v_{g}}$ field with magnitude quite constant with depth, only changing very close to $500 \mathrm{db}$ (left panels of Figures 11c,d). On the contrary, Dipole 2 has a baroclinic structure, with the magnitude of $\overrightarrow{v_{g}}$ rapidly decreasing between 200 and $300 \mathrm{db}$ (right panels of Figures 11c,d). The different character of both dipoles is also visible in the $w_{q g}$ field, now with the offshore dipole having greater velocities than the near-shore dipole. Therefore, both the $\theta$ and velocity fields point at a different origin, with a near-barotropic Dipole 1 likely originating through the blockage of the $\mathrm{CC}$ by the islands and a baroclinic Dipole 2 resulting from the instability of the baroclinic frontal jet.

Recently, Sangrà et al. (2009) reported the region south of the Canary Islands to be a main source for long-lived westward propagating eddies, which lasted over 
six months while travelling more than $2000 \mathrm{~km}$. This region was found to be the origin for over $40 \%$ of the long-lived eddies observed in the northeastern subtropical Atlantic, with an average formation rate between 3 and 4 eddies per year. These authors used remote sensing techniques to identify the source region but the imagery lacked enough resolution near coast. They emphasized the importance of the island effect but raised the possibility that some of the mesoscale activity was generated at the CTZ. Our results support the idea that the instability of a coastal baroclinic zone is a potentially very important eddy generation mechanism. This is the likely source of the northeastern eddies in the study area: C1 in Figure 3, which is the cyclone of Dipole 2 in Figure 11, and the anticyclone and cyclone located to the right of this cyclone (Figures 10 and 11).

\subsection{Fluorescence distribution}

Early research has indicated that frontal regions, as transition zones between different water masses with high mesoscale activity, are sites of enhanced primary production (Holligan, 1981; Jones and Halpern, 1981; Falkowski et al., 1991). Indeed, satellite images (Pacheco and Hernández-Guerra, 1999) and field data from the Canary region (Arístegui et al., 1997; Barton et al., 1998, 2004) have shown that chlorophyll may be enhanced when associated with specific mesoscale structures. The principal factors influencing phytoplankton growth are the availability of solar radiation and inorganic nutrients, the latter supplied through both vertical movements and horizontal transport from the upwelling region (e.g. filaments in Figure 3). Regarding the first factor, the depth of the euphotic zone has been reported to be quite constant in our study area, i.e. about $100 \mathrm{~m}$ (Neuer et al., 2007). Therefore, it does not appear to play a key role on the spatial distribution of pri- 
mary production. Since no nutrient data are available from the cruise we cannot justifiably address the second issue, i.e. nutrient supply. However, based on the available fluorescence distributions, we can make some brief considerations on the potential role of mesoscale structures in modulating primary production.

Physical processes in mesoscale structures may either accumulate/retain the existing biomass or stimulate in situ growth of phytoplankton. Cyclones dome isopycnals and, therefore, tend to upwell subsurface nutrients into the euphotic zone; conversely anticyclones depress isopycnals making difficult the conection between the nutrients and light (Arístegui et al., 1997). However, the role of isopycnals doming or deepening on the nutrients supply can only be effective during relatively short periods immediately after eddy generation. After some time, typically of the order of a few eddy revolutions or about 10-20 days (Sangrà et al., 2005; Sangrà et al., 2007), the eddy is fully formed and the maximum isopycnal displacements have been attained. Beyond this time the eddy starts to decay and the isopycnal displacements decrease. At these later stages the mean tangential flow is closely in geostrophic balance so that vertical and radial advective motions are negligible, and vertical secondary circulations within the eddy may only arise as a result of diffusive processes. This possibly justifies some observed differences between the cyclonic and anticyclonic eddies: the proximity of subsurface nutrients in cyclonic eddies likely favours diapycnal transfer, contrary to what happens in anticyclonic eddies.

These ideas are supported by our data set. We find a substantial correlation between the vertical profiles of fluorescence and $w_{q g}$ down to $110 \mathrm{db}$ in those re- 
gions with high mesoscale activity $(\mathrm{r} \geq| \pm 0.6|, \mathrm{p} \leq 0.1)$. This result fundamentally points to the isopycnals (and DFM) as caused by the vertical velocities $w_{q g}$ associated to mesoscale structures. As indicated earlier (Section 4.2), the depth of the $17.4{ }^{\circ} \mathrm{C}$ isotherm approximately follows the base of the surface mixed layer. Since the depth of the surface mixed-layer shoals towards the coast, we expect there should be a correlation between the depth of the $17.4^{\circ} \mathrm{C}$ isotherm and DFM depth. We indeed find such a high correlation, $r=0.68, \mathrm{p} \leq 0.01$. Nevertheless, the intensity of the DFM does not remain constant. There is a negative correlation $(\mathrm{r}=-0.37, \mathrm{p} \leq 0.01)$ between the depth of the $17.4{ }^{\circ} \mathrm{C}$ isotherm and the intensity of the DFM, indicating that the shallower the DFM the more intense it becomes, e.g. cyclonic eddies appear with higher fluorescence levels.

\section{Conclusions}

We have examined the characteristics of the CTZ, with special emphasis on the 3D circulation patterns, in a $100 \mathrm{~km}$ long and $200 \mathrm{~km}$ wide region south of the Canary Islands. The dominant characteristic is the coastal upwelling frontal system, some $30 \mathrm{~km}$ wide and occupying the top $300 \mathrm{db}$ of the water column. This frontal region is characterized by an intense baroclinic jet, whose intensity decreases from 0.18 to $0.05 \mathrm{~m} \mathrm{~s}^{-1}$ between the sea surface and $300 \mathrm{db}$, that separates upwelled waters from the offshore region.

Over the slope, between the frontal region and the continental platform, we find upwelled waters which are relatively homogeneous down to the sea floor. At pressures less than 200-300 db we find a weak southward flow that changes little with pressure, which we identify as the barotropic contribution of the CUC. Just 
below and down to some 400-500 db we find the poleward undercurrent, a region of order 10-20 km wide characterized by isoneutrals deepening towards the sea bottom with associated northward flow.

A traditional perspective of the offshore region would anticipate isopycnals gently rising towards the coast, the large-scale signature of the CC. However, in our relatively small region this picture is masked by the presence of substantial mesoscale activity. An important finding is that these vortices have two different origins: approximately barotropic vortices are generated through the traditional topographic mechanism, i.e. the interaction of the $\mathrm{CC}$ and the Canary Islands, while highly baroclinic vortices originated through instabilities of the frontal system, in the form of meanders that eventually detach as vortices to both sides of the front.

The mesoscale vertical velocity field is characterized by a patchy field superposed onto a zonal gradient. The distribution of QG mesoscale vertical velocities is intermittent all over the domain, changing with horizontal and vertical position. These velocities become very intense in phases of meanders and vortices, up to $-18 \mathrm{~m} \mathrm{day}^{-1}$ and $12 \mathrm{~m} \mathrm{day}^{-1}$, but their patchy spatial structure causes the associated transport to be small, of order $0.01 \mathrm{~Sv}$. This contrasts with other non-zero mean contributions to the vertical velocity field (upwelling, linear Ekman pumping and shear-induced diapycnal transfer) that change zonally with distance from the coast. The upwelling vertical field, positive in the upwelling region, has mean values of $0.7 \mathrm{~m} \mathrm{day}^{-1}$ and a total contribution of $0.08 \mathrm{~Sv}$. The diapycnal contribution is mostly due to the subcritical character of the frontal region, with an es- 
timated total transport of $0.18 \mathrm{~Sv}$. This corresponds to mean positive velocities of $5.2 \mathrm{~m} \mathrm{day}^{-1}$ but likely with much larger maximum values in the baroclinic frontal jet. Linear Ekman pumping is the slowest one, about $0.3 \mathrm{~m} \mathrm{day}^{-1}$, as it takes takes place over a potentially large offshore region, and its integrated transport is -0.05 Sv; non-linear Ekman pumping reaches maximum values of several meters per day but its integrated transport is negligible. An observed increase of DFM values in the frontal and upwelling regions points at an important role played by these vertical flows. Further offshore a moderate increase in DFM appears to be associated with peaks of $w_{q g}$, intermittently developing at different phases of the evolving eddies.

\section{Appendix A: Error estimates for vertical velocities}

Diagnostic estimates of vertical velocities are affected by errors arising from theoretical assumptions, instrumental precision, aliasing of high-frequency motions, station distribution, lack of sinopticity in the field sampling, and/or the interpolation method. In order to test the accuracy of the $w_{q g}$ fields, the objective analysis has been repeated changing its controlling parameters within realistic limits. We have explored the results of letting the correlation scale change between 15 and $25 \mathrm{~km}$, the noise-to-signal ratio between 0.01 and 0.1 , and the cut-off wavelength between 0 and $40 \mathrm{~km}$. Overall, the shape of the $w_{q g}$ fields remains similar to that obtained using the optimal values. However, we obtained $w_{q g}$ differences of the order of $25 \%, 60 \%$ and $50 \%$ associated to changes in the correlation scale, noise-to-signal ratio and the cut-off wavelength, respectively. Those

errors associated to the separation between stations and to the eventual lack of 
synopticity of the observations are typically of the order of $30 \%$, as evaluated by Gomis and Pedder (2005) and Gomis et al. (2005) for a cruise similar to the one here analyzed. Therefore, we may conclude that the shape and order of magnitude of the $w_{q g}$ field are likely correct although the precise values are unknown.

An error associated to the $w_{d i a}$ computation may be estimated from the changes in the geostrophic mass imbalance in the surface layers arising from the above sensitivity analysis. For this purpose we examined the mass imbalances in the two surface layers. The differences between these new calculations and the $w_{\text {dia }}$ value computed with the optimal parameters $\left(5.2 \mathrm{~m} \mathrm{day}^{-1}\right)$, reach up to $4 \mathrm{~m} \mathrm{day}^{-1}$. The largest differences correspond to those analyses which directly influence the smoothness of the interpolated variables. However, the $w_{\text {dia }}$ is quite insensitive to the cut-off scale.

Finally, the sensitivity of the $w_{u p}$ is assessed by accumulating those errors in the measured wind stress and recalculating the coastal upwelling Ekman transport divided by the upwelling area. In this way we find variations of $\pm 0.3 \mathrm{~m} \mathrm{day}^{-1}$ around a mean estimate of $0.7 \mathrm{~m} \mathrm{day}^{-1}$.

\section{Acknowledgments}

We would like to thank Des Barton, Iván Alonso, Dong Ping Wang and Francisco Machín for their useful comments and suggestions, and the crew of the R/V Hespérides for their help at sea. We are very grateful to Jack Barth and two anonymous reviewers for their time and many constructive comments that helped 
to improve significantly the original manuscript. This work has been supported by a grant from the Canary government to the first author and through the Spanish government project Conafrica (CTM2004-02319). Part of this work was written while the first author was at the School of Marine and Atmospheric Sciences (Stony Brook University, New York) with funding from the Canary government.

\section{References}

Allen, J., Smeed, D., 1996. Potential Vorticity and Vertical Velocity at the IcelandFærœs Front. Journal of Physical Oceanography 26, 2611-2634.

Arhan, M., De Verdiére, A., Mémery, L., 1994. The Eastern Boundary of the Subtropical North Atlantic. Journal of Physical Oceanography 24, 1295-1316.

Arístegui, J., Sangrà, P., Hernández-León, S., Cantón, M., Hernández-Guerra, A., Kerling, J., 1994. Island-induced eddies in the Canary Islands. Deep Sea Research 41, 1509-1525.

Arístegui, J., Tett, P., Hernández-Guerra, A., Basterretxea, G., Montero, M., Wild, K., Sangrà, P., Hernández-León, S., Cantón, M., García-Braun, J., et al., 1997. The influence of island-generated eddies on chlorophyll distribution: a study of mesoscale variation around Gran Canaria. Deep Sea Research 44, 71-96.

Barton, E., Arístegui, J., Tett, P., Cantón, M., García-Braun, J., HernándezLeón, S., Nykjaer, L., Almeida, C., Almunia, J., Ballesteros, S., Basterretxea, G., Escánez, J., García-Weill, L., Hernández-Guerra, A., López-Laatzen, F., Molina, R., Montero, M., Navarro-Pérez, E., Rodríguez, J., van Lenning, K., 
Vélez, H., Wild, K., 1998. The transition zone of the Canary Current upwelling region. Progress in Oceanography 41, 455-504.

Barton, E., Arístegui, J., Tett, P., Navarro-Pérez, E., 2004. Variability in the Canary Islands area of filament-eddy exchanges. Progress in Oceanography 62, 71-94.

Bower, A., 1989. Potential vorticity balances and horizontal divergence along particle trajectories in Gulf Stream meanders east of Cape Hatteras. Journal of Physical Oceanography 19, 1669-1681.

Bowman, M., Iverson, R., 1978. Estuarine and plume fronts. Oceanic fronts in coastal processes, 87-104.

Bretherton, F., Davis, R., Fandry, C., 1976. A technique for objective analysis and design of oceanographic experiments applied to MODE-73. Deep Sea Research 23, 559-582.

Brockman, C., Hughes, P., Tomczak, M., 1977. Currents, winds and stratification in the NW African upwelling region during early 1975. Data Report 32, Institut für Meereskunde an der Christian-Albrechts-Universitat, Kiel, Germany, 45 pp.

Csanady, G., 1979. The pressure field along the western margin of the North Atlantic. Journal of Geophysical Research 84, 4905-4915.

Csanady, G., Pelegrí, J., 1995. Vorticity balance of boundary currents. Journal of Marine Research 53, 171-187.

Falkowski, P., Ziemann, D., Kolber, Z., Bienfang, P., 1991. Role of eddy pumping in enhancing primary production in the ocean. Nature $352,55-58$. 
Fiekas, V., Elken, J., Müller, T., Aitsam, A., Zenk, W., 1992. A view of the Canary Basin thermocline circulation in winter. Journal of Geophysical Research 97, $12495-12510$.

Fraile-Nuez, E., Machín, F., Vélez-Belchí, P., López-Laatzen, F., Borges, R., Benítez-Barrios, V., Hernández-Guerra, A., 2010. Nine years of mass transport data in the eastern boundary of the North Atlantic Subtropical Gyre. Journal of Geophysical Research 115, C09009, doi:10.1029/2010JC006161.

Ganachaud, A., 2003. Large-scale mass transports, water mass formation, and diffusivities estimated from World Ocean Circulation Experiment (WOCE) hydrographic data. Journal of Geophysical Research 108, 3213, doi:10.1029/2002JC001565.

Gandin, L., 1965. Objective Analysis of Meteorological Fields. Israel Program for Scientific Translations.

García-Muñoz, M., Arístegui, J., Pelegrí, J., Antoranz, A., Ojeda, A., Torres, M., 2005. Exchange of carbon by an upwelling filament off Cape Ghir (NW Africa). Journal of Marine Systems 54, 83-95.

Gill, A., 1982. Atmosphere-ocean dynamics. Vol. 30. Academic Press, 662 pp.

Gill, A., Clarke, A., 1974. Wind-induced upwelling, coastal currents and sea-level changes. Deep Sea Research 21, 325-345.

Gomis, D., García, M., López, O., Pascual, A., 2002. Quasi-geostrophic 3D circulation and mass transport in the western Bransfield Strait during Austral summer 1995/96. Deep Sea Research 49, 603-621. 
Gomis, D., Pascual, A., Pedder, M., 2005. Errors in dynamical fields inferred from oceanographic cruise data:: Part ii. the impact of the lack of synopticity. Journal of Marine Systems 56 (3-4), 334-351.

Gomis, D., Pedder, M., 2005. Errors in dynamical fields inferred from oceanographic cruise data Part I. The impact of observation errors and the sampling distribution. Journal of Marine Systems 56, 317-333.

Gomis, D., Ruiz, S., Pedder, M., 2001. Diagnostic analysis of the 3D ageostrophic circulation from a multivariate spatial interpolation of CTD and ADCP data. Deep Sea Research 48, 269-295.

Hagen, E., Zülicke, C., Feistel, R., 1996. Near-surface structures in the Cape Ghir filament off Morocco. Oceanologica acta 19, 577-598.

Hernández-Guerra, A., Fraile-Nuez, E., Borges, R., López-Laatzen, F., VélezBelchí, P., Parrilla, G., Müller, T., 2003. Transport variability in the Lanzarote passage (eastern boundary current of the North Atlantic subtropical Gyre). Deep Sea Research 50, 189-200.

Hernández-Guerra, A., Fraile-Nuez, E., López-Laatzen, F., Martínez, A., Parrilla, G., Vélez-Belchí, P., 2005. Canary Current and North Equatorial Current from an inverse box model. Journal of Geophysical Research 110, C12019, doi:10.1029/2005JC003032.

Hernández-Guerra, A., López-Laatzen, F., Machín, F., de Armas, D., Pelegrí, J., 2001. Water masses, circulation and transport in the eastern boundary current of the North Atlantic subtropical gyre. Scientia Marina 65, 177-186. 
Hernández-Guerra, A., Machín, F., Antoranz, A., Cisneros-Aguirre, J., Gordo, C., Marrero-Díaz, A., Martínez, A., Ratsimandresy, A., Rodríguez-Santana, A., Sangrà, P., López-Laatzen, F., Parrilla, G., Pelegrí, J., 2002. Temporal variability of mass transport in the Canary Current. Deep Sea Research 49, 3415-3426.

Hernández-Guerra, A., Nykjaer, L., 1997. Sea surface temperature variability off north-west Africa: 1981-1989. International Journal of Remote Sensing 18, 2539-2558.

Holligan, P., 1981. Biological implications of fronts on the northwest European continental shelf. Philosophical Transactions of the Royal Society of London. Series A, Mathematical and Physical Sciences, 547-562.

Hoskins, B., Draghici, I., Davies, H., 1978. A new look at the omega-equation. Quarterly Journal of the Royal Meteorological Society 104, 31-38.

Hsiung, J., 1986. Mean surface energy fluxes over the global ocean. Journal of Geophysical Research 91, 10585-10606.

Hughes, P., Barton, E., 1974. Stratification and water mass structure in the upwelling area off northwest Africa in April/May 1969. Deep Sea Research 21, $1-628$.

Huyer, A., Barth, J., Kosro, P., Shearman, R., Smith, R., 1998. Upper-ocean water mass characteristics of the California Current, summer 1993. Deep Sea Research 45, 1411-1442.

Jackett, D., McDougall, T., 1997. A Neutral Density Variable for the Worlds Oceans. Journal of Physical Oceanography 27, 237-263. 
Jiménez, B., Sangrà, P., Mason, E., 2008. A numerical study of the relative importance of wind and topographic forcing on oceanic eddy shedding by tall, deep water islands. Ocean Modelling 22, 146-157.

Jones, B., Halpern, D., 1981. Biological and physical aspects of a coastal upwelling event observed during March-April 1974 off northwest Africa. Deep Sea Research 28, 71-81.

Kara, A., Rochford, P., Hurlburt, H., 2000. An optimal definition for ocean mixed layer depth. Journal of Geophysical Research 105, 16.

Käse, R., Price, J., Richardson, P., Zenk, W., 1986. A quasi-synoptic survey of the thermocline circulation and water mass distribution within the Canary Basin. Journal of Geophysical Research 91, 9739-9748.

Käse, R., Zenk, W., Sanford, T., Hiller, W., 1985. Currents, fronts and eddy fluxes in the Canary Basin. Progress in Oceanography 14, 231-257.

Keyser, D., Shapiro, M., 1986. A review of the structure and dynamics of upperlevel frontal zones. Monthly Weather Review 114, 452-499.

Knoll, M., Hernández-Guerra, A., Lenz, B., López-Laatzen, F., Machín, F., Müller, T., Siedler, G., 2002. The Eastern Boundary Current system between the Canary Islands and the African Coast. Deep Sea Research 49, 3427-3440.

Krauss, W., 1986. The North Atlantic current. Journal of Geophysical Research 91, 5061-5074.

Kundu, P., Beardsley, R., 1991. Evidence of a critical Richardson number in 
moored measurements during the upwelling season off Northern California. Journal of Geophysical Research 96, 4855-4868.

Leetma, A., Bunker, A., 1978. Updated charts of the mean annual wind stress, convergences in the Ekman layer, and Sverdrups transports in the North Atlantic. Journal of Marine Research 36, 311-322.

Liu, W., Tang, W., 1996. Equivalent neutral wind. Vol. 96. National Aeronautics and Space Administration, Jet Propulsion Laboratory, California Institute of Technology.

Machín, F., Hernández-Guerra, A., Pelegrí, J., 2006a. Mass fluxes in the Canary Basin. Progress in Oceanography 70, 416-447.

Machín, F., Pelegrí, J., 2006b. Effect of the Canary Islands in the blockage and mixing of the North Atlantic eastern water masses. Geophysical Research Letters 33, L04605, doi:10.1029/2005GL025048.

Manríquez, M., Fraga, F., 1982. The distribution of water masses in the upwelling region off Northwest Africa in November. Rapports et Proces-verbeaux des Reunions Conseil International pour l'Exploration de la Mer 180, $39-47$.

Mittelstaedt, E., 1983. The upwelling area off northwest Africa. A description of phenomena related to coastal upwelling. Progress in Oceanography 12, $307-$ 331.

Mittelstaedt, E., Pillsbury, D., Smith, R., 1975. Flow patterns in the Northwest African upwelling area. Ocean Dynamics 28, 145-167. 
Mouriño, B., Fernández, E., Alves, M., 2004. Thermohaline structure, ageostrophic vertical velocity fields and phytoplankton distribution and production in the North East Atlantic subtropical front. Journal of Geophysical Research 109, C04020, doi:10.1029/2003JC001990.

Müller, T., Siedler, G., 1992. Multi-year current time series in the eastern North Atlantic Ocean. Journal of Marine Research 50, 63-98.

Neuer, S., Cianca, A., Helmke, P., Freudenthal, T., Davenport, R., Meggers, H., Knoll, M., Santana-Casiano, J., González-Dávila, M., Rueda, M., Llinás, O., 2007. Biogeochemistry and hydrography in the eastern subtropical North Atlantic gyre. Results from European time-series station ESTOC. Progress in Oceanography $72,1-29$.

Nykjaer, L., van Camp, L., 1994. Seasonal and interannual variability of coastal upwelling along northwest Africa and Portugal from 1981 to 1991. Journal of Geophysical Research 99, 14197-14208.

Olbers, D., Wenzel, M., Willebrand, J., 1985. The interference of North Atlantic circulation patterns from climatological hydrographic data. Reviews of Geophysics 23, 313-356.

Pacheco, M., Hernández-Guerra, A., 1999. Seasonal variability of recurrent phytoplankton pigment patterns in the Canary Islands area. International Journal of Remote Sensing 20, 1405-1418.

Parrilla, G., Neuer, S., Le Traon, P., Fernández-Suárez, E., 2002. Topical studies in oceanography: Canary Islands Azores Gibraltar Observations (CANIGO)- 
Volume 1: Studies in the northern Canary Islands basin. Deep Sea Research 49, 3409-3413.

Pastor, M., Pelegrí, J., Hernández-Guerra, A., Font, J., Salat, J., Emelianov, M., 2008. Water and nutrient fluxes off Northwest Africa. Continental Shelf Research 28, 915-936.

Pelegrí, J., Arístegui, J., Cana, L., González-Dávila, M., Hernández-Guerra, A., Hernández-León, S., Marrero-Díaz, A., Montero, M., Sangrà, P., SantanaCasiano, M., 2005a. Coupling between the open ocean and the coastal upwelling region off northwest Africa: water recirculation and offshore pumping of organic matter. Journal of Marine Systems 54, 3-37.

Pelegrí, J., Marrero-Díaz, A., Ratsimandresy, A., 2006. Nutrient irrigation of the North Atlantic. Progress in Oceanography 70, 366-406.

Pelegrí, J., Marrero-Díaz, A., Ratsimandresy, A., Antoranz, A., Cisneros-Aguirre, J., Gordo, C., Grisolía, D., Hernández-Guerra, A., Laiz, I., Martínez, A., Parrilla, G., Pérez-Rodríguez, P., Rodríguez-Santana, A., Sangrà, P., 2005b. Hydrographic cruises off northwest Africa: the Canary Current and the Cape Ghir region. Journal of Marine Systems 54, 39-63.

Pelegrí, J., Richman, J., 1993. On the role of shear mixing during transient coastal upwelling. Continental Shelf Research 13, 1363-1400.

Pickett, M., Paduan, J., 2003. Ekman transport and pumping in the California Current based on the US Navy's high-resolution atmospheric model (COAMPS). Journal of Geophysical Research 108, 3327, doi:10.1029/2003JC001902. 
Pollard, R., Regier, L., 1992. Vorticity and Vertical Circulation at an Ocean Front. Journal of Physical Oceanography 22, 609-625.

Rudnick, D., 1996. Intensive surveys of the Azores front. 2. Inferring the geostrophic and vertical velocity fields. Journal of Geophysical Research 101, 16291-16304.

Sangrà, P., Auladell, M., Marrero-Díaz, A., Pelegrí, J., Fraile-Nuez, E., Rodríguez-Santana, A., Martín, J., Mason, E., Hernández-Guerra, A., 2007. On the nature of oceanic eddies shed by the Island of Gran Canaria. Deep Sea Research 54, 687-709.

Sangrà, P., Pascual, A., Rodríguez-Santana, A., Machín, F., Mason, E., McWilliams, J., Pelegrí, J., Dong, C., Rubio, A., Arístegui, J., et al., 2009. The Canary Eddy Corridor: A major pathway for long-lived eddies in the subtropical North Atlantic. Deep Sea Research 56, 2100-2114.

Sangrà, P., Pelegrí, J., Hernández-Guerra, A., Arregui, I., Martín, J., MarreroDíaz, A., Martínez, A., Ratsimandresy, A., Rodríguez-Santana, A., 2005. Life history of an anticyclonic eddy. Journal of Geophysical Research 110, C03021, doi:10.1029/2004JC002526.

Shearman, R., Barth, J., Kosro, P., 1999. Diagnosis of the three-dimensional circulation associated with mesoscale motion in the California Current. Journal of Physical Oceanography 29, 651-670.

Stern, M., 1965. Interaction of a uniform wind stress with a geostrophic vortex. Deep Sea Research 12, 355-367. 
Stramma, L., Siedler, G., 1988. Seasonal changes in the North Atlantic subtropical gyre. Journal of Geophysical Research 93, 8111-8118.

Tejera, A., García-Weil, L., Heywood, K., Cantón-Garbín, M., 2002. Observations of oceanic mesoscale features and variability in the Canary Islands area from ERS-1 altimeter data, satellite infrared imagery and hydrographic measurements. International Journal of Remote Sensing 23, 4897-4916.

Tett, P., Arístegui, J., Barton, D., Basterretxea, G., De Armas, J., Escánez, J., León, S., Lorenzo, L., Montero, N., 2002. Steady-state DCM dynamics in Canaries waters. Deep Sea Research 49 (17), 3543-3559.

Tintoré, J., Gomis, D., Alonso, S., Parrilla, G., 1991. Mesoscale dynamics and vertical motion in the Alborán Sea. Journal of Physical Oceanography 21, 811823.

Tomczak, M., 1978. Distribution of water masses in surface-layers of Northwest African upwelling area. Geophysical Journal of the Royal Astronomical Society $53,183$.

van Aken, H., van Haren, H., Maas, L., 2007. The high-resolution vertical structure of internal tides and near-inertial waves measured with an adcp over the continental slope in the bay of biscay. Deep Sea Research 54, 533-556.

Van Camp, L., Nykjaer, L., Mittelstaedt, E., Schlittenhardt, P., 1991. Upwelling and boundary circulation off Northwest Africa as depicted by infrared and visible satellite observations. Progress in Oceanography 26, 357-402. 
Figure 1: (a) Study area (solid grey box) off NW Africa with the mean wind components from QuikSCAT during the CONAFRICA cruise period (22 March - 7 April 2006). (b) Detail of the study area showing the CTD stations together with the 50, 200, 500, 1000 and $2000 \mathrm{~m}$ isobaths.

Figure 2: Time series of averaged daily QuikSCAT winds over the surveyed area; the cruise period is highlighted.

Figure 3: (a) Satellite SST $\left({ }^{\circ} \mathrm{C}\right)$ image for March 29 with the geostrophic current vectors at the sea surface (relative to $500 \mathrm{db}$ ) as obtained using the cruise hydrographic data. (b) Satellite Chl a $\left(\mathrm{mg} \mathrm{m}^{-3}\right)$ image for April 7. A, C and F labels refer to the anticyclonic eddy, the cyclonic eddy and the filaments, respectively. The white line corresponds to the $200 \mathrm{~m}$ isobath, approximately at the shelf break.

Figure 4: Horizontal distributions at $20 \mathrm{db}$ of (a) dynamic height (dyn m; gray bar) and $\overrightarrow{v_{g}}\left(10^{-2}\right.$ $\left.\mathrm{m} \mathrm{s}^{-1}\right)$, referred to $500 \mathrm{db}$; (b) in situ fluorescence (V; grey bar) and $\theta\left({ }^{\circ} \mathrm{C}\right)$ with $0.2^{\circ} \mathrm{C}$ contour intervals; (c) $S$ with 0.04 contour intervals. The thick dashed black lines denote the dynamic height contours of 0.625 and 0.64 dyn $\mathrm{m}$ and the gray line shows the $200 \mathrm{~m}$ isobath. The small dots represent the grid-points.

Figure 5: Horizontal distributions at $50 \mathrm{db}, 110 \mathrm{db}, 245 \mathrm{db}$ and $410 \mathrm{db}$, of (a) dynamic height (dyn $\mathrm{m}$ ) and $\overrightarrow{v_{g}}\left(10^{-2} \mathrm{~m} \mathrm{~s}^{-1}\right)$, referred to $500 \mathrm{db}$, (b) in situ fluorescence (V; color bar) and potential temperature $\left({ }^{\circ} \mathrm{C}\right)$, and (c) Ro superimposed on the SST image for March 29. Contour interval is $0.2^{\circ} \mathrm{C}$ for $\theta$ and 0.05 for $R o$. White lines represent the 0.625 and 0.64 dyn $\mathrm{m}$ isolines of dynamic height at $20 \mathrm{db}$. The bold contours in the $\theta$ field at $110 \mathrm{db}$ is the $17.4{ }^{\circ} \mathrm{C}$ isotherm.

Figure 6: $\theta$-S diagram using data from all cruise stations. Averaged $\theta$-S curves for the upwelled, frontal and offshore waters. The colour scale represents the pressure of each grid-point, and the dashed lines correspond to $\sigma_{\theta}=26.6,26.8$ and $27.1 \mathrm{~kg} \mathrm{~m}^{-3}$. 
Figure 7: Across-shore sections of (left) $v_{g}\left(10^{-2} \mathrm{~m} \mathrm{~s}^{-1}\right)$ and $\gamma_{n}\left(\mathrm{~kg} \mathrm{~m}^{-3}\right)$, and (right) in situ fluorescence (V; grey bar) and $\theta\left({ }^{\circ} \mathrm{C}\right.$ ) at (a) $27.95^{\circ} \mathrm{N}$, (b) $27.55^{\circ} \mathrm{N}$ and (c) $27.25^{\circ} \mathrm{N}$. Dashed contours indicate southward velocities. The elongated upper left panels represent $u_{g}\left(10^{-2} \mathrm{~m} \mathrm{~s}^{-1}\right)$ at each transect, with positive values indicating eastward flow. The bold contours in the $\theta$ field denote the $17.4{ }^{\circ} \mathrm{C}$ isotherm. The frontal position is indicated by arrows at the top of the left panels.

Figure 8: (a) Layer-integrated mass transports for the north (crosses, solid line), south (x-marks, dotted line), east (stars, dashed-dotted line) and west (circle, solid line) grid sections. Mass conservation in the box is represented by the black line. Positive/negative signs are assigned to divergent/convergent flow out-of/into the box. (b) Accumulated mass transport (A.M.T.) at $27.7^{\circ} \mathrm{N}$, with the integration starting at the African coast. Positive/negative accumulated mass transport values denote northward/sorthward flow for the Canary Upwelling Current (CUC) and the Canary Current (CC).

Figure 9: Across-shore sections of $w_{q g}\left(\mathrm{~m} \mathrm{day}^{-1}\right)$ and $u_{g}\left(10^{-2} \mathrm{~m} \mathrm{~s}^{-1}\right)$ along (a) $27.95^{\circ} \mathrm{N}$, (b) $27.55^{\circ} \mathrm{N}$ and (c) $27.25^{\circ} \mathrm{N}$. Colored contours represent the $v_{g}$ field. Gray lines represent isoneutrals contoured at intervals of $0.05 \mathrm{~kg} \mathrm{~m}^{-3}$. The frontal position is indicated by arrows at the top of each panel.

Figure 10: Horizontal distributions of mesoscale vertical velocity $w_{q g}\left(\mathrm{~m} \mathrm{day}^{-1}\right)$ at $50 \mathrm{db}, 110 \mathrm{db}$, $245 \mathrm{db}$ and $410 \mathrm{db}$. Red and blue areas respectively indicate upward and downward velocities. Superimposed are the $\zeta_{g}$ fields (solid/dashed gray lines indicate positive/negative values, plotted at $0.4 \times 10^{-5} \mathrm{~s}^{-1}$ intervals) together with the 0.625 and 0.64 dyn $\mathrm{m}$ isolines of dynamic height at $20 \mathrm{db}$ (dashed black curves). 
Figure 11: (a) Horizontal distribution of Ro at $20 \mathrm{db}$ with dots indicating the position of Dipole 1 and Dipole 2. Left and right panels in (b) through (d) correspond to the sections across Dipoles 1 and 2, respectively. (b) Sections of $\theta\left({ }^{\circ} \mathrm{C}\right.$; black lines) and in situ fluorescence (V; grey lines). Contour interval is $1^{\circ} \mathrm{C}$ for $\theta$, and $0.4 \mathrm{~V}$ for fluorescence. (c) Sections of $w_{q g}\left(\mathrm{~m} \mathrm{day}^{-1}\right)$ and the zonal $u_{g}\left(10^{-2} \mathrm{~m} \mathrm{~s}^{-1}\right)$, referred to $500 \mathrm{db}$. (d) Sections of $w_{q g}\left(\mathrm{~m} \mathrm{day}^{-1}\right)$ and the meridional $v_{g}$ $\left(\mathrm{cm} \mathrm{s}^{-1}\right)$, referred to $500 \mathrm{db}$. In panels (c) and (d) the gray lines represent isoneutrals contoured at intervals of $0.1 \mathrm{~kg} \mathrm{~m}^{-3}$. 
a)

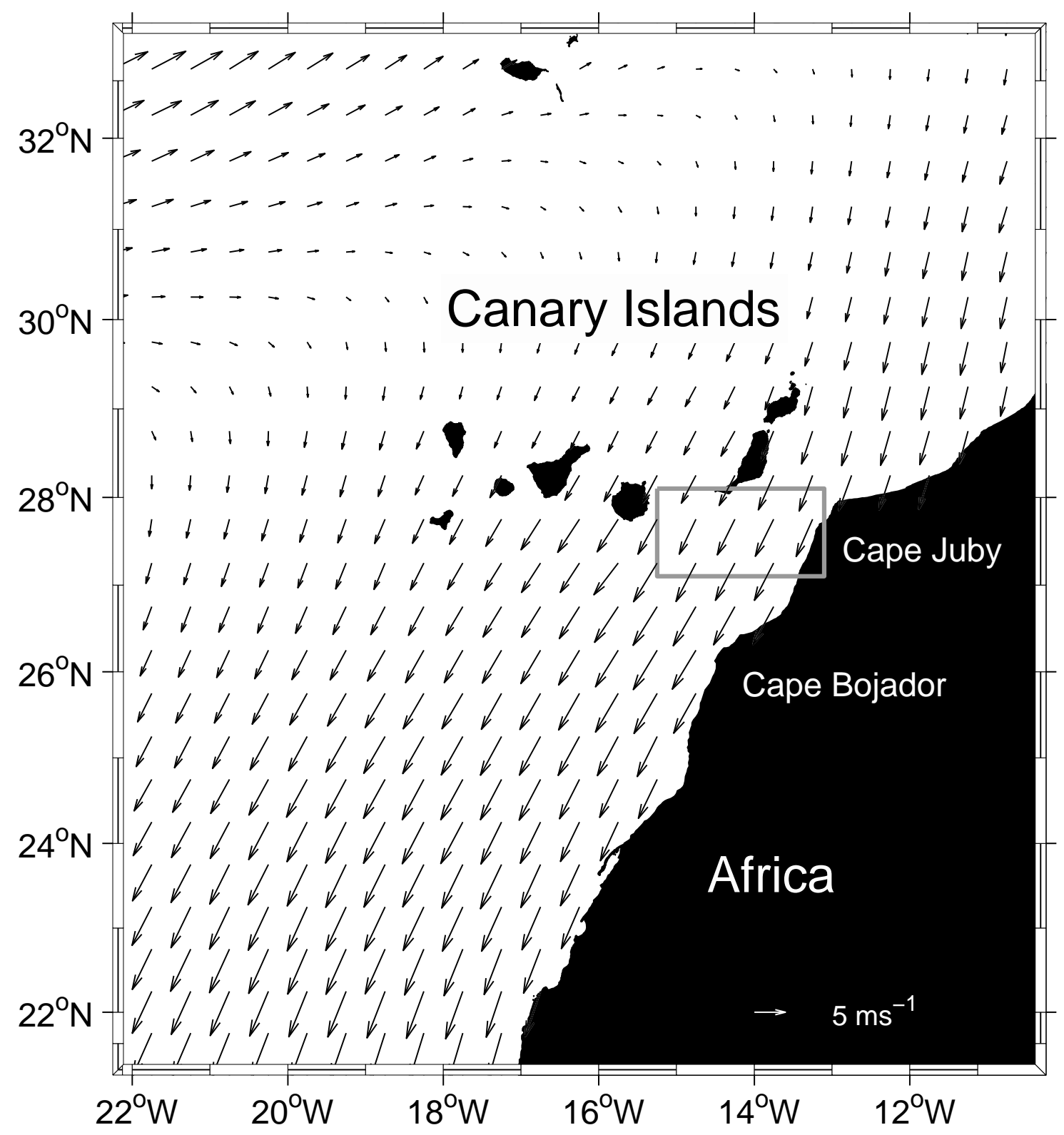

b)

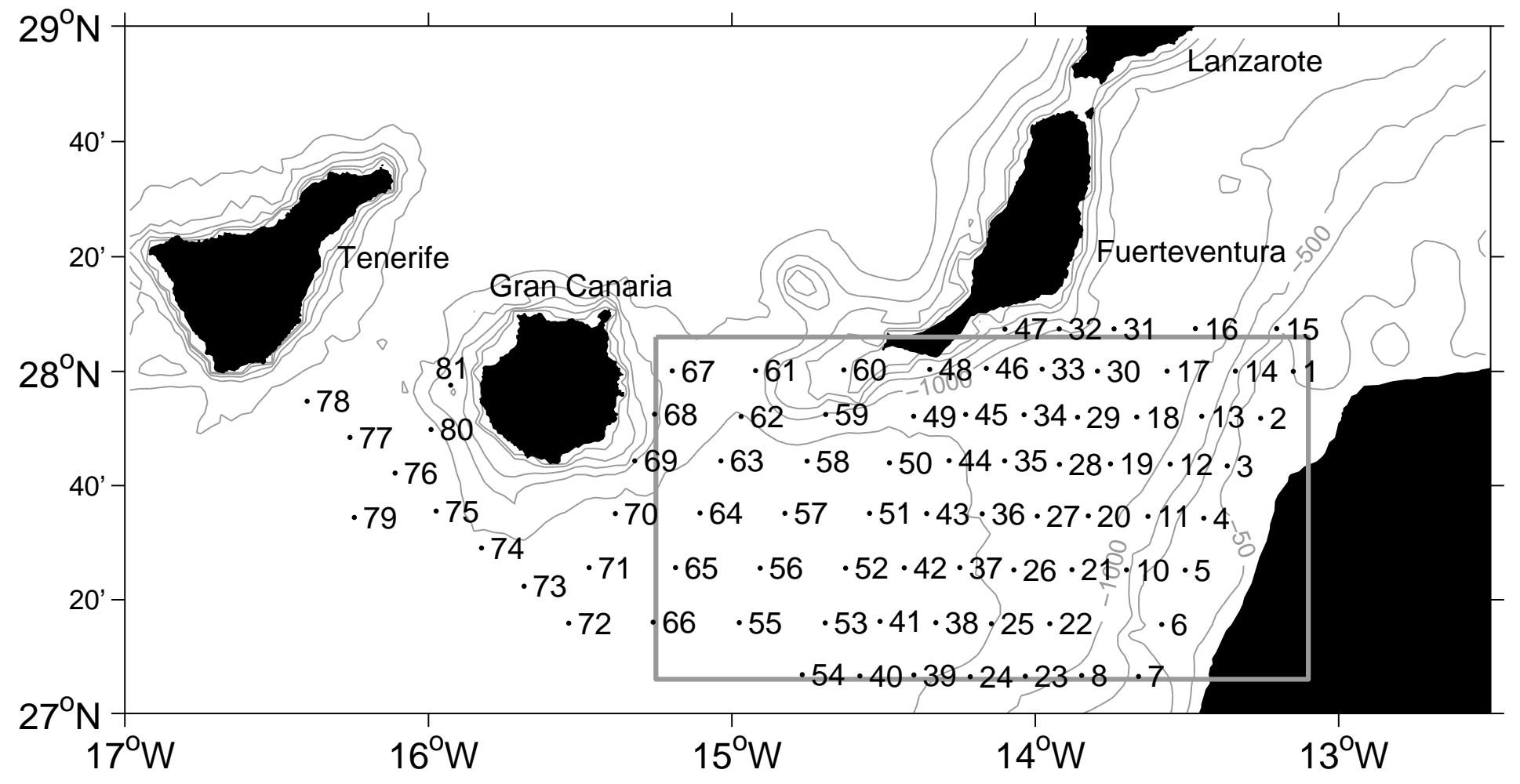




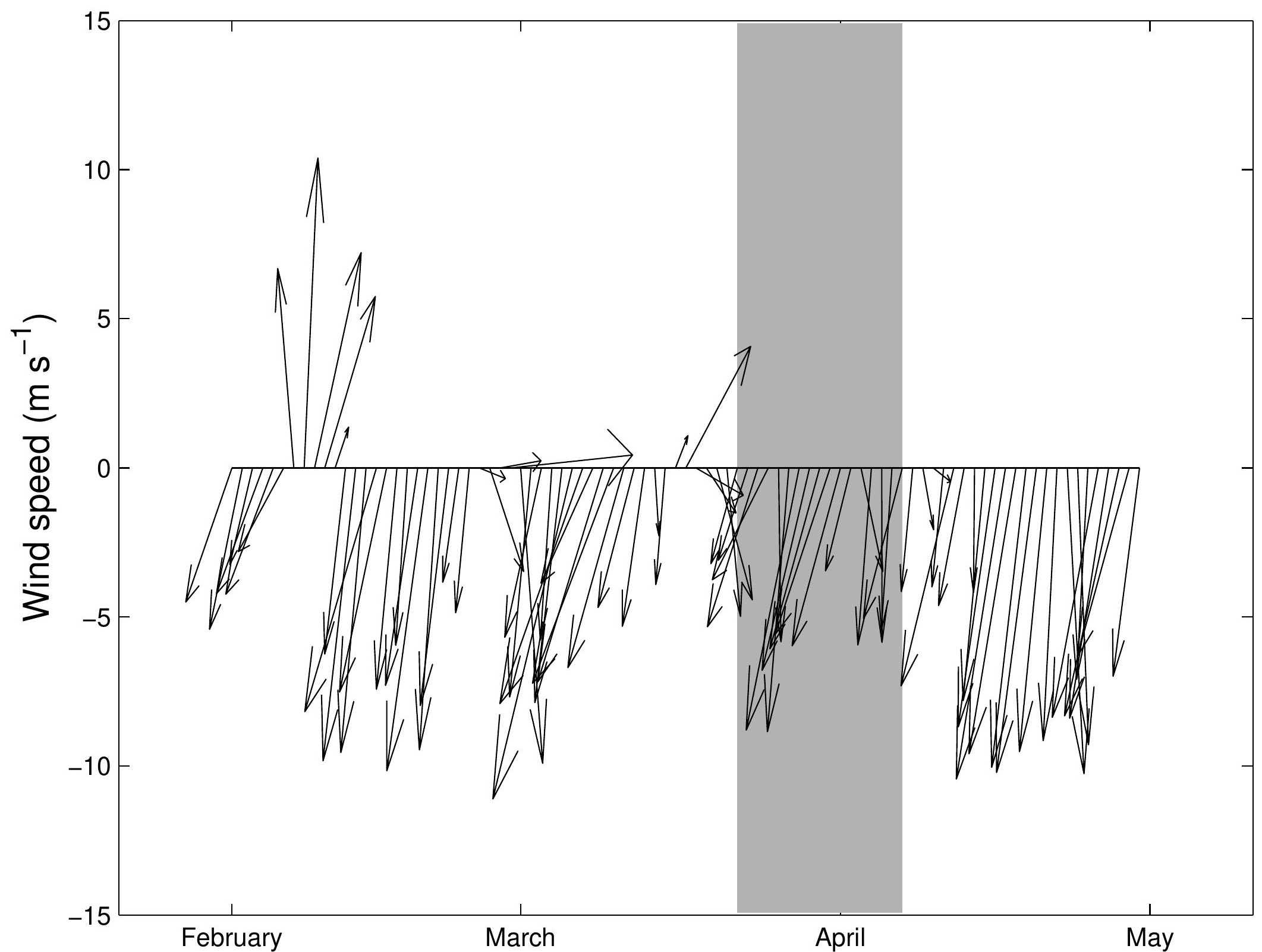


a) $D_{20 / 500}, \vec{v}_{g}$

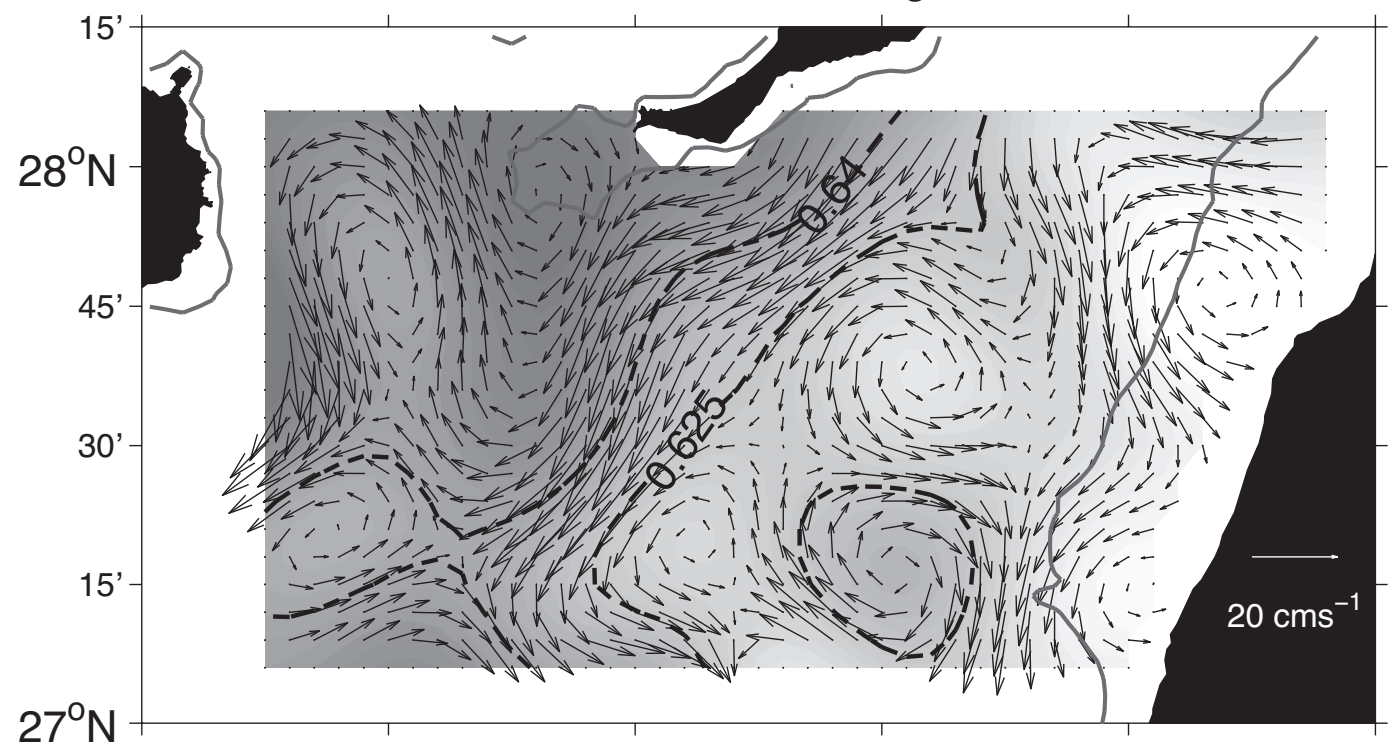

0.66
-0.65
-0.64
0.63
0.62
0.61
0.6

b) $\mathrm{F}, \theta$
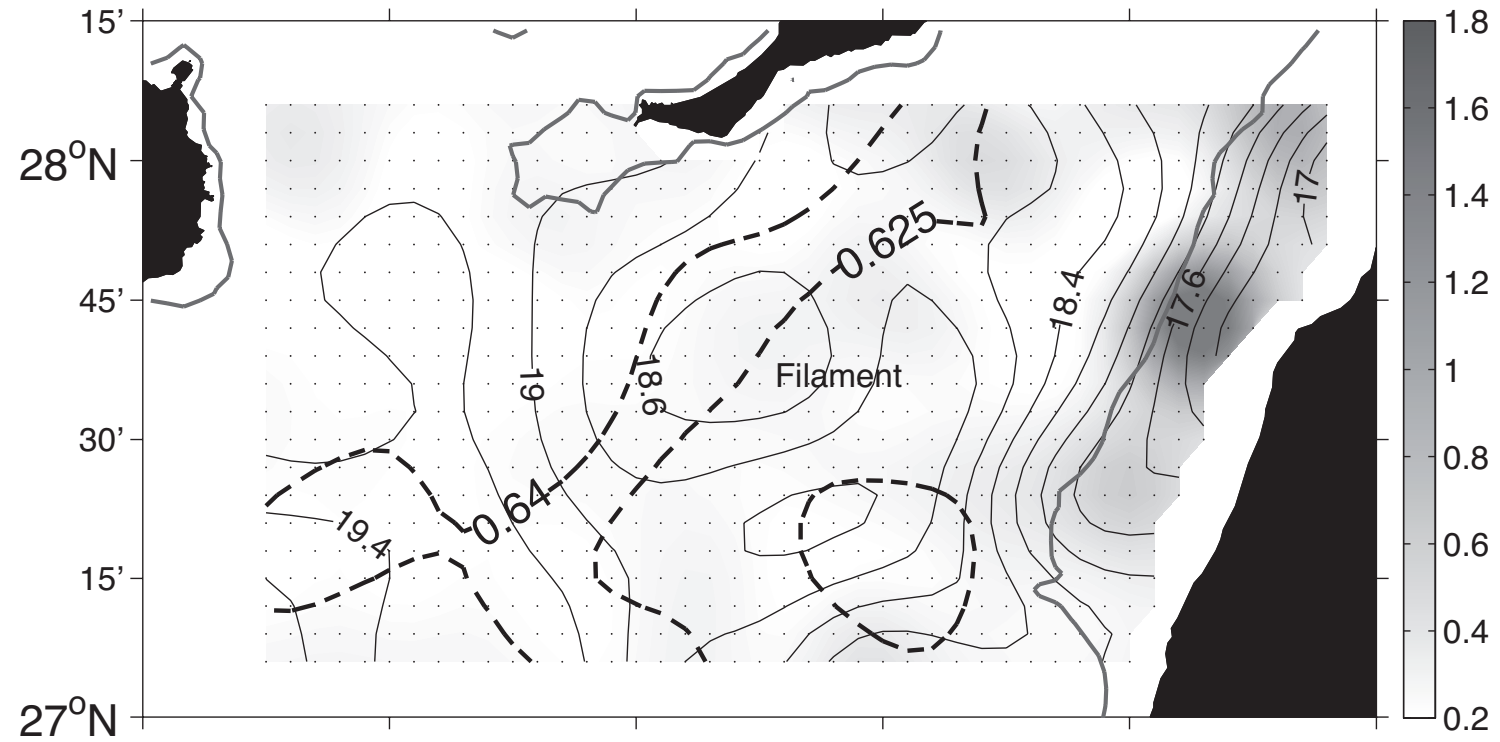

c) $\mathrm{S}$

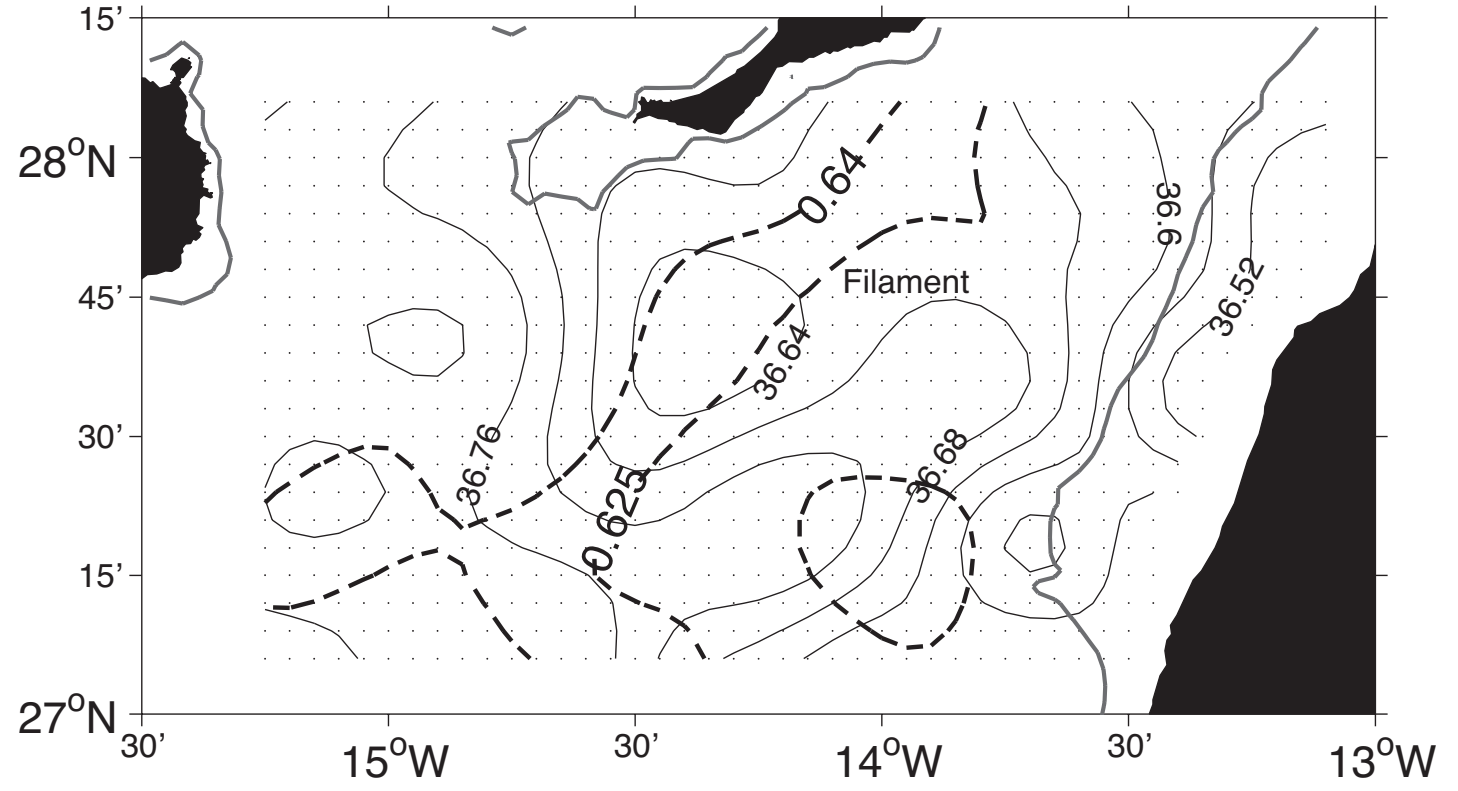


Figure5

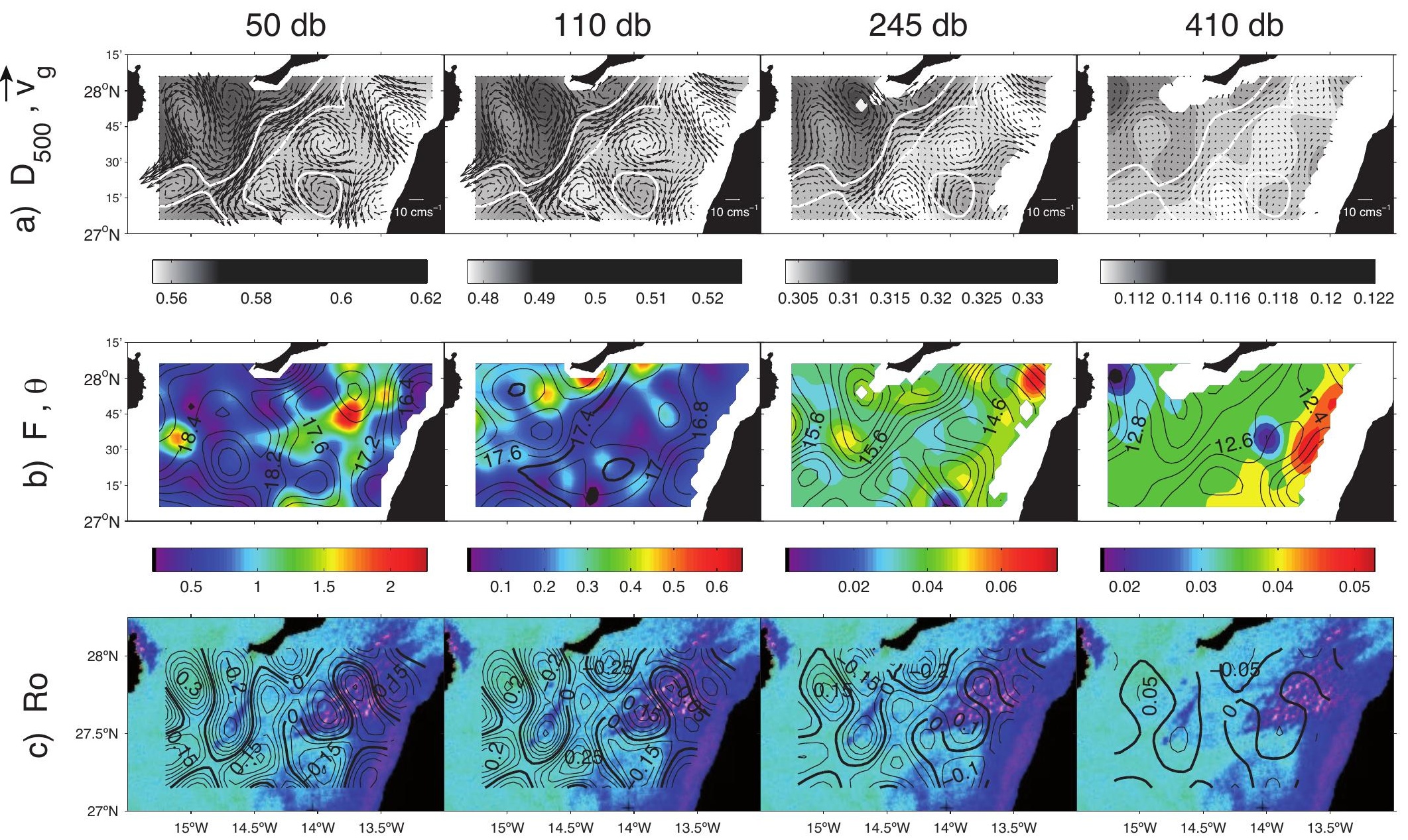




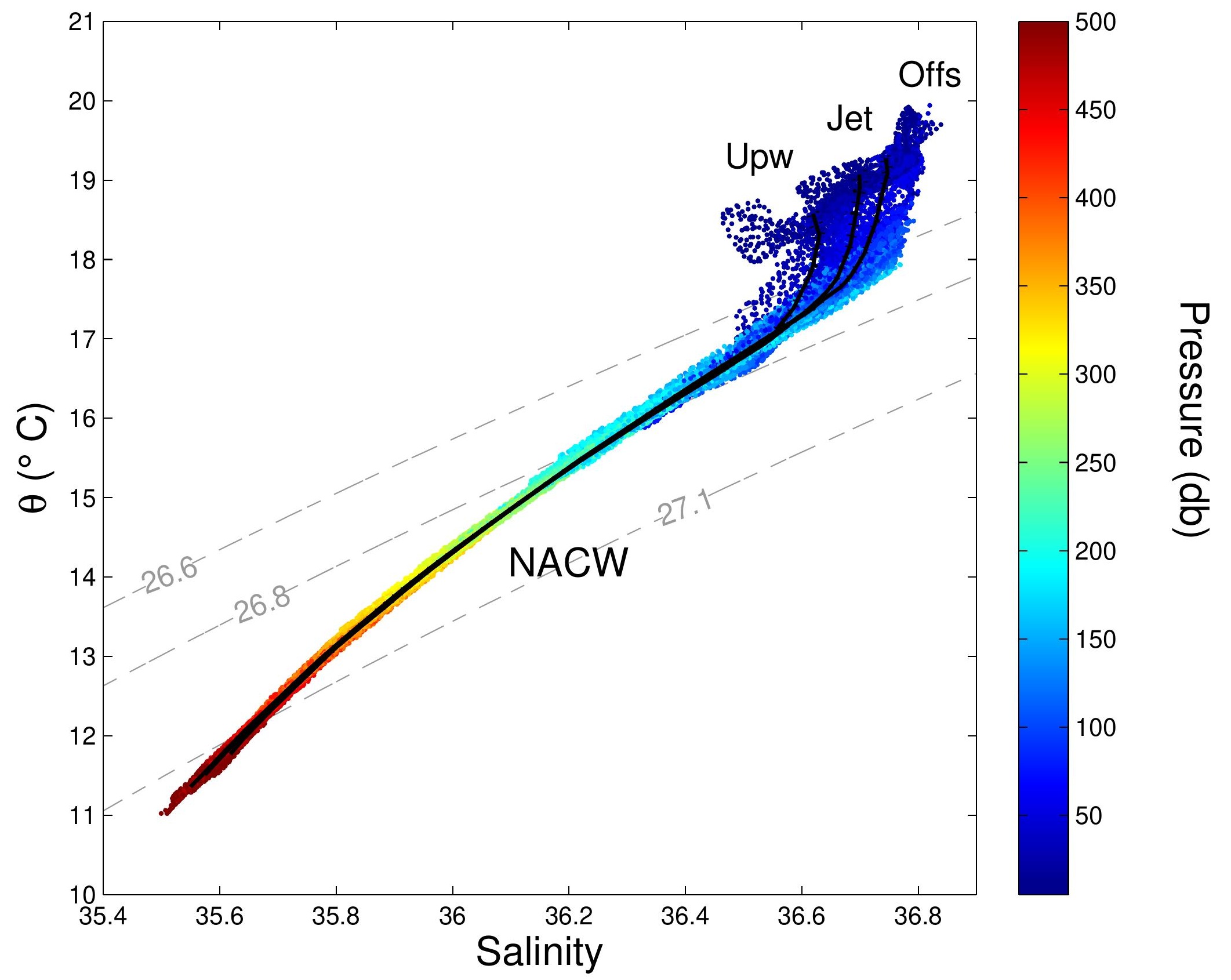


a)
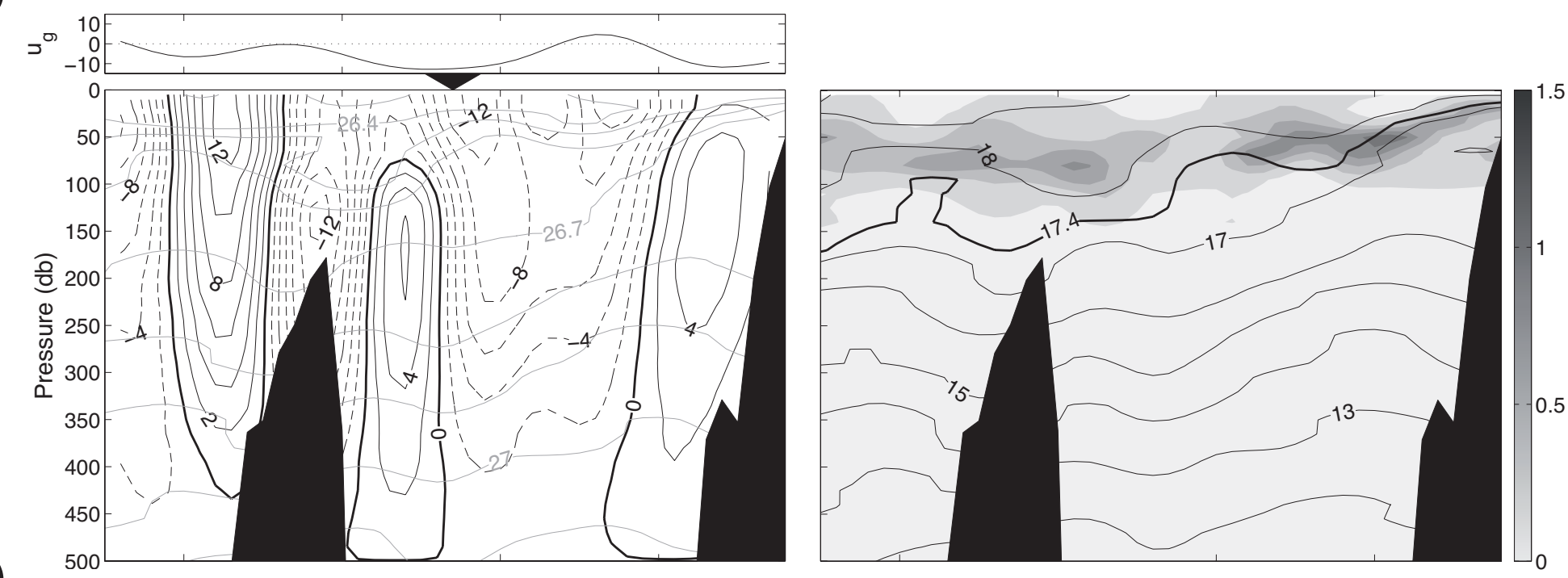

$27.95^{\circ} \mathrm{N}$

b)

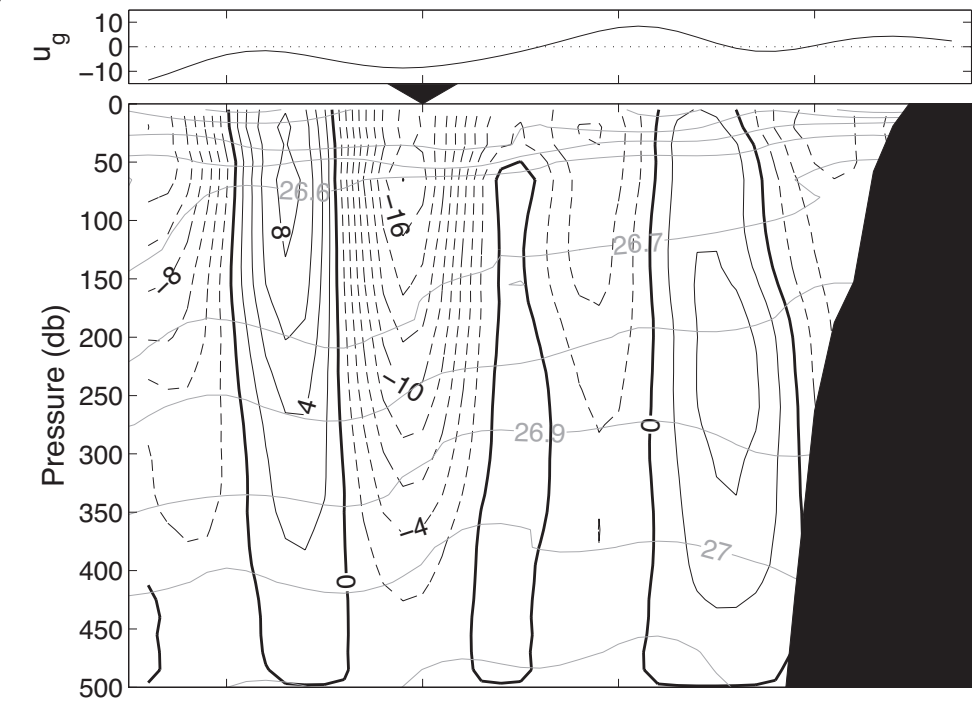

C)
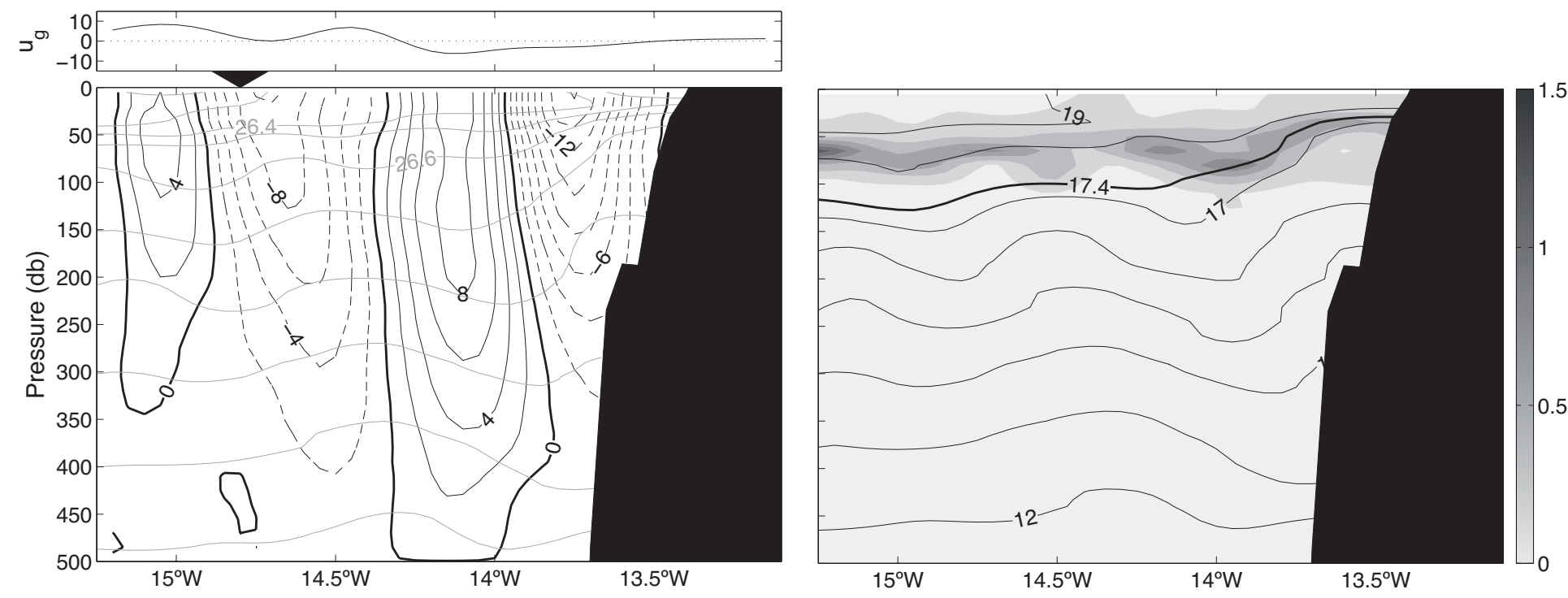

$27.25^{\circ} \mathrm{N}$

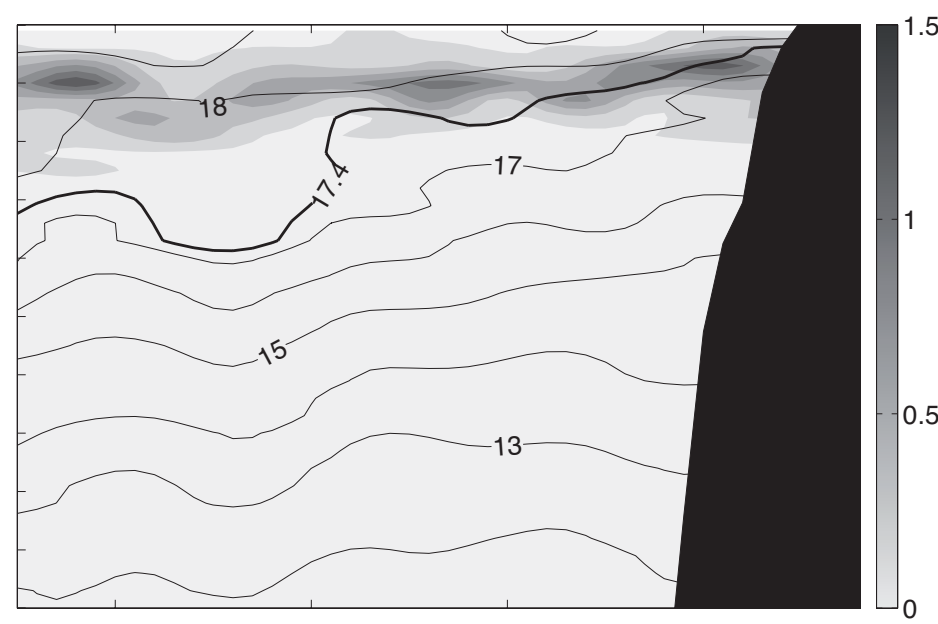

$27.55^{\circ} \mathrm{N}$ 


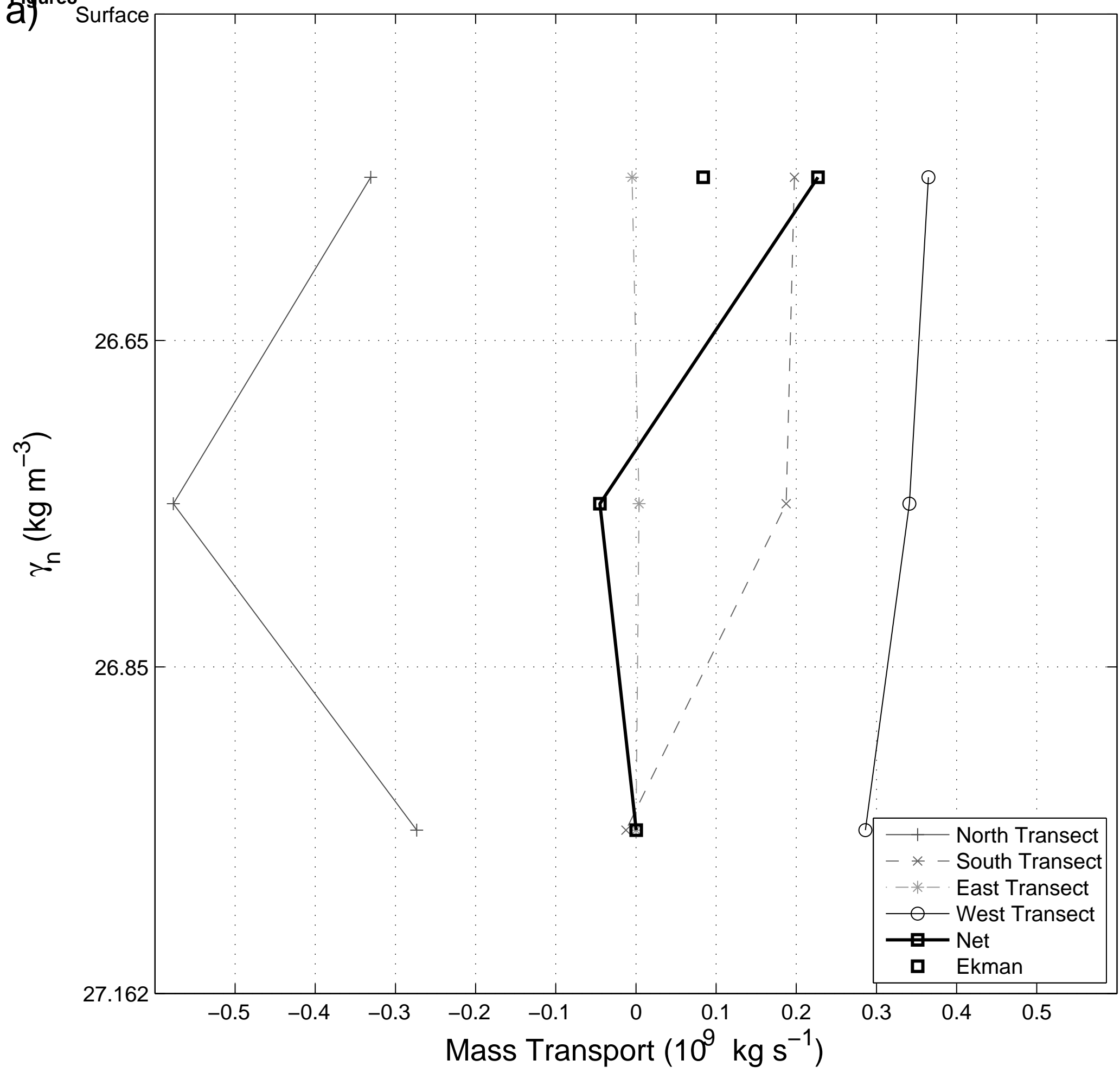

b)

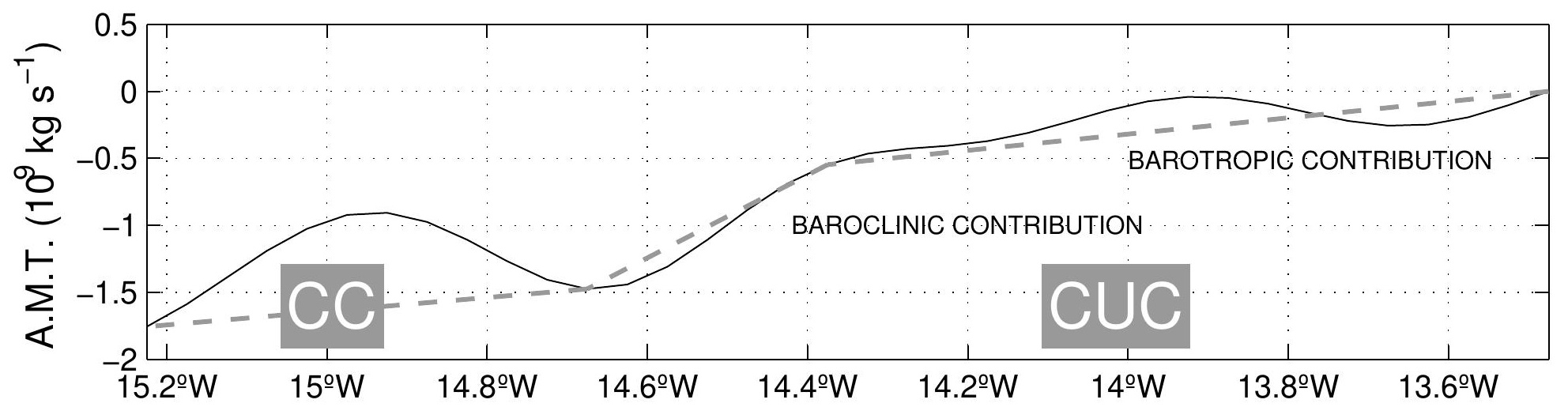


b)

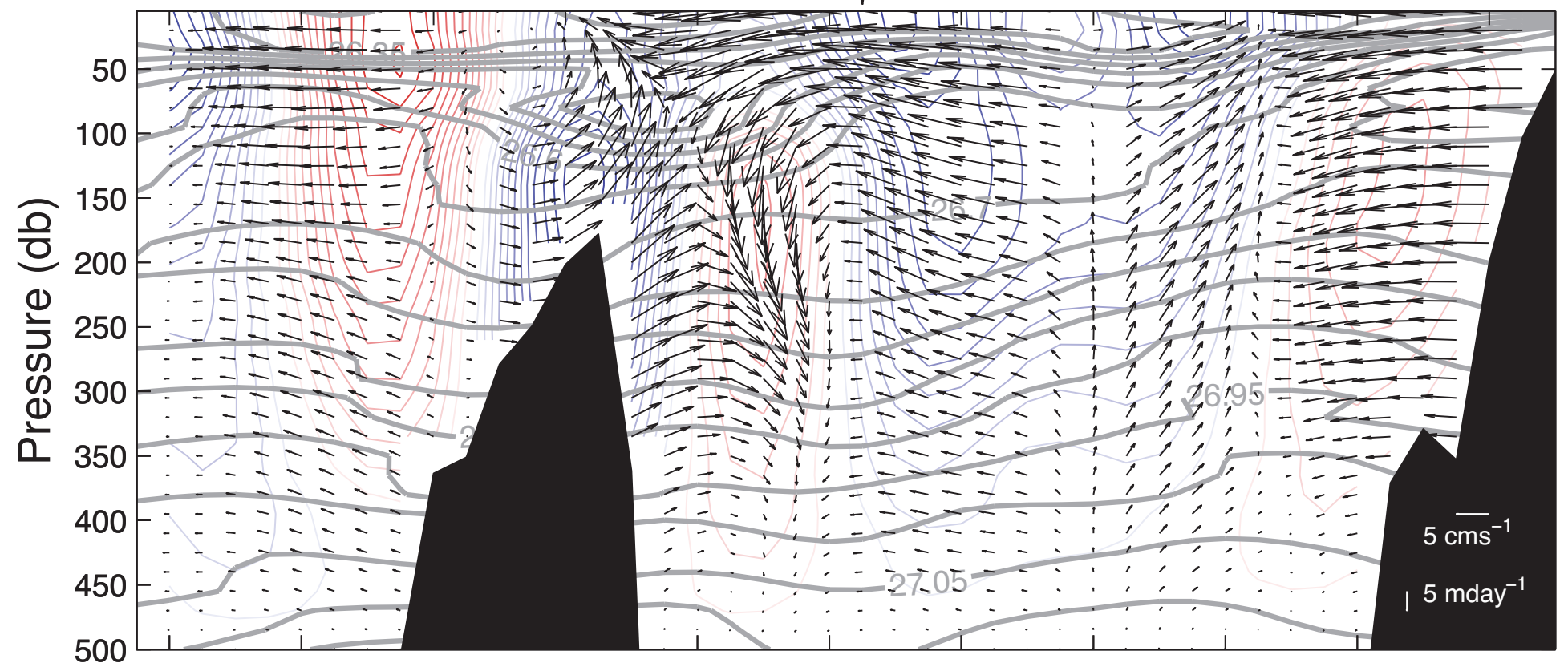

c)
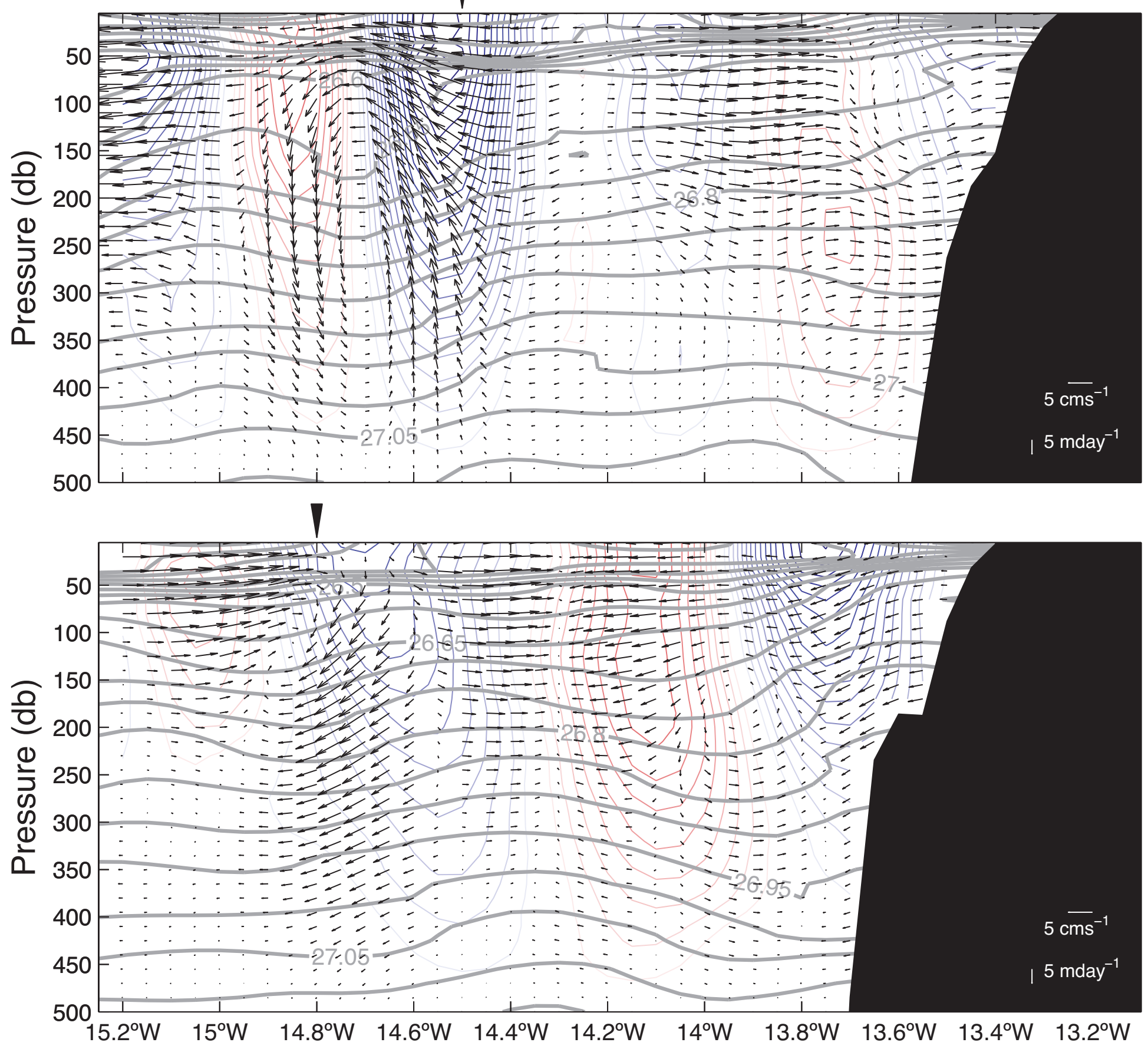


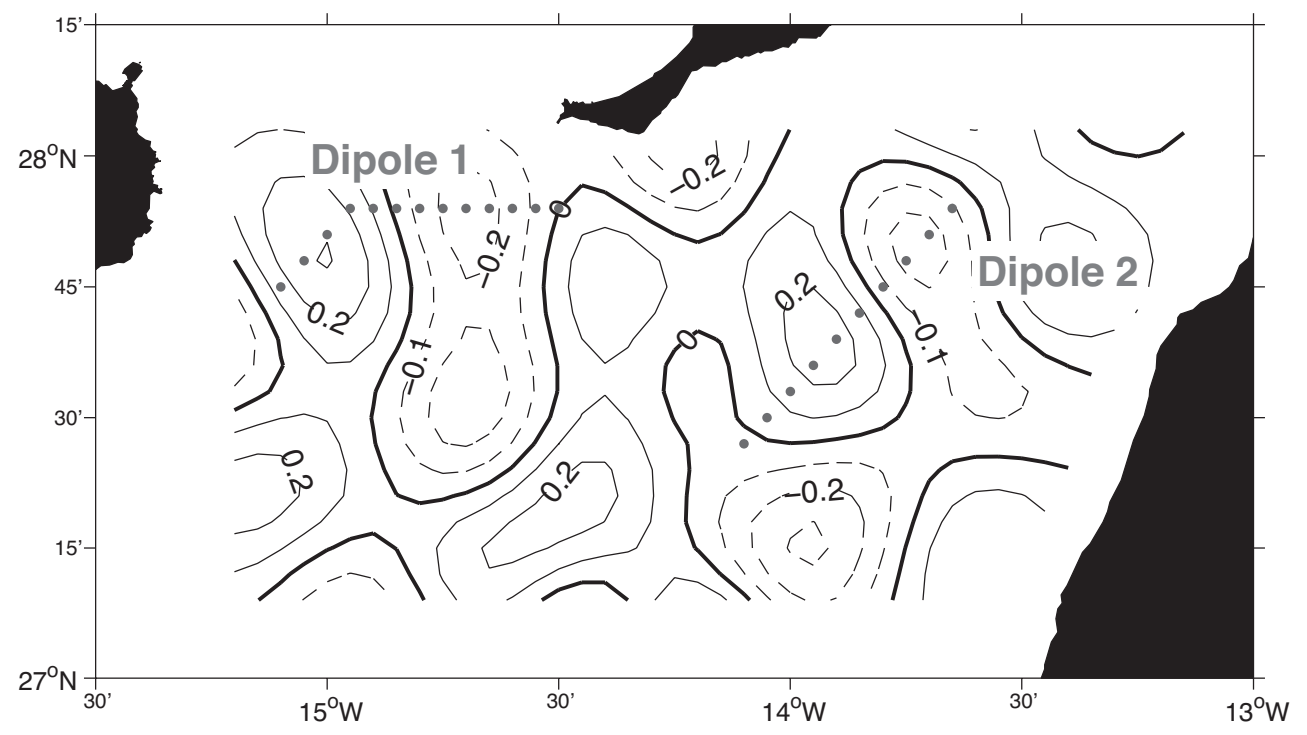

b)

Dipole 1

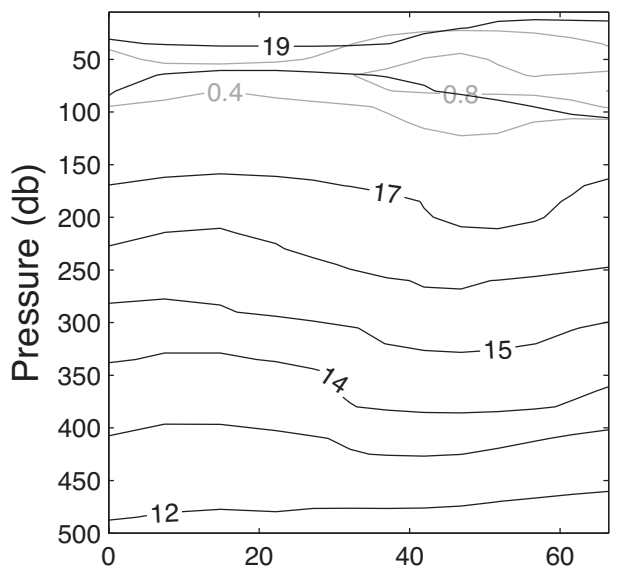

d)
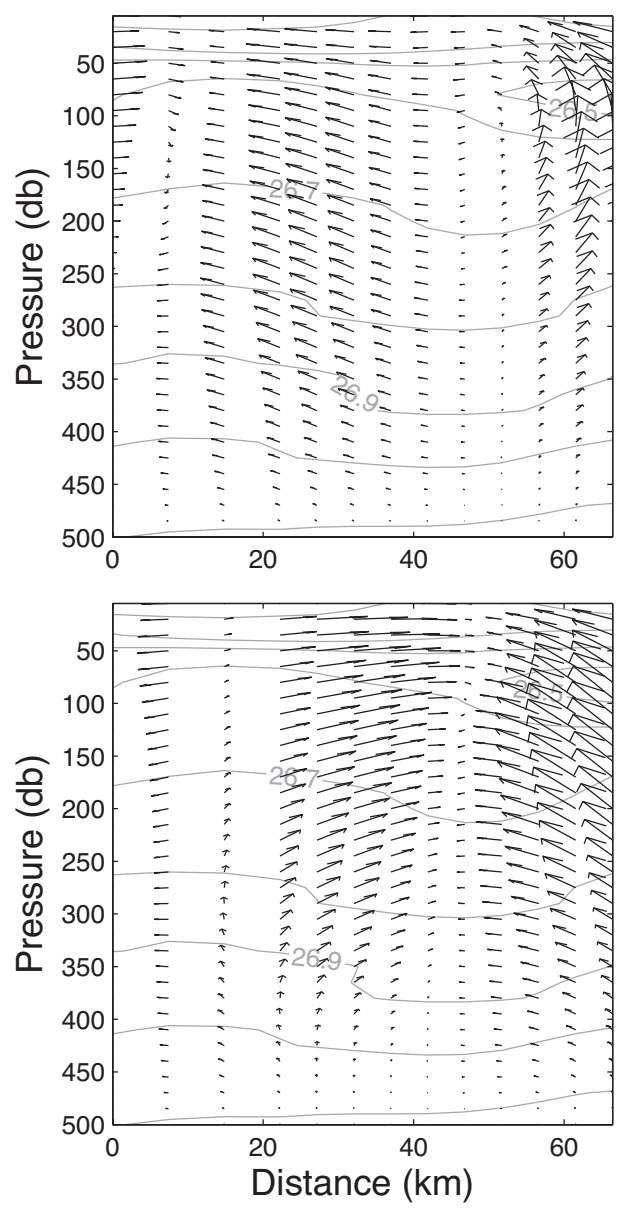

Dipole 2
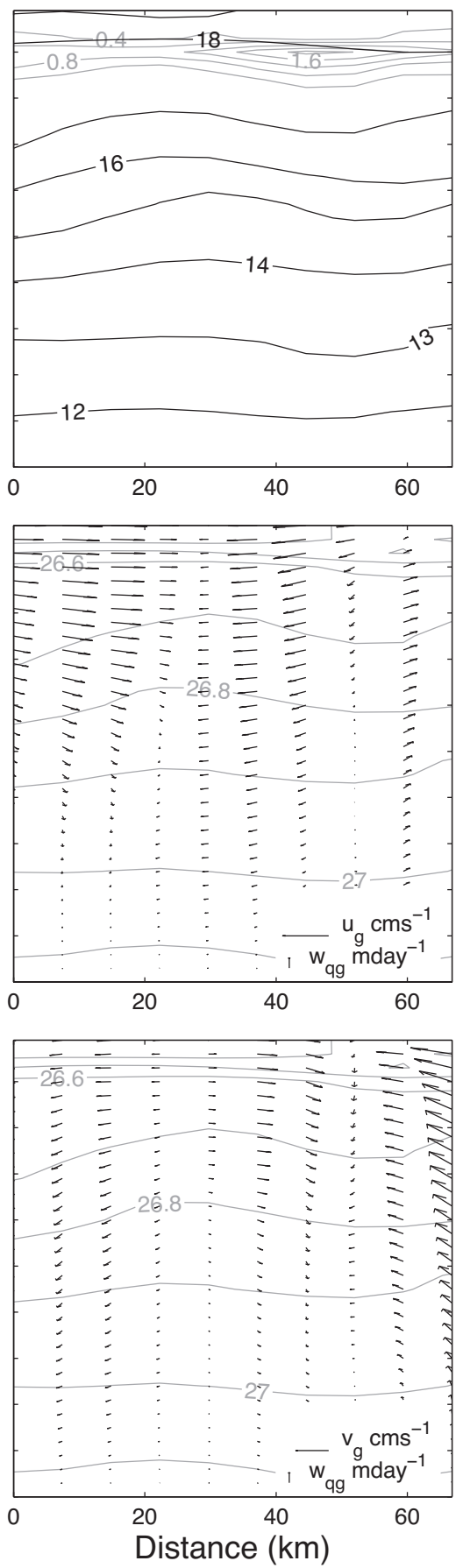